\title{
ON-THE-JOB SEARCH AND THE CYCLICAL DYNAMICS OF THE LABOR MARKET
}

by Michael U. Krause and Thomas A. Lubik

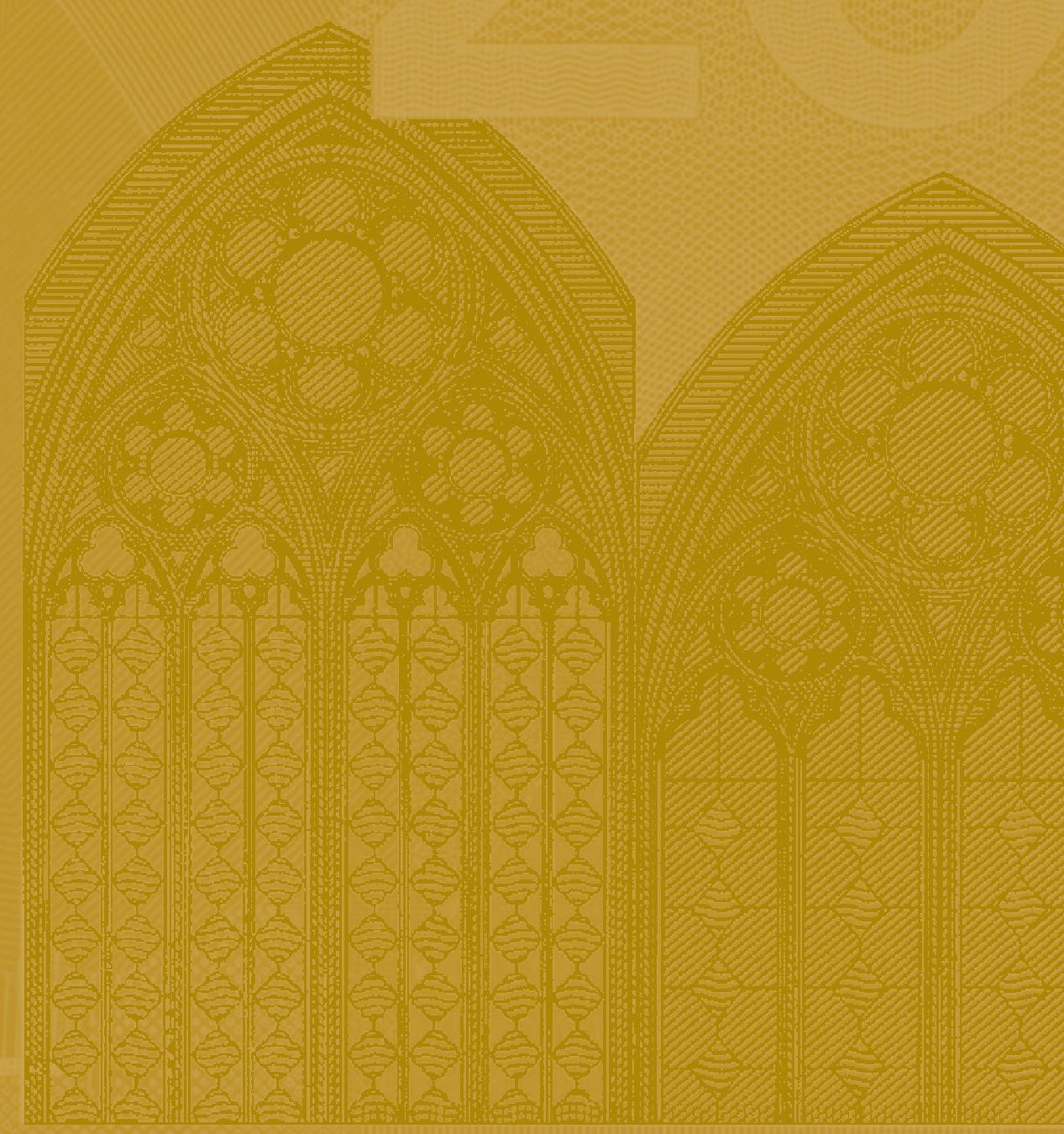




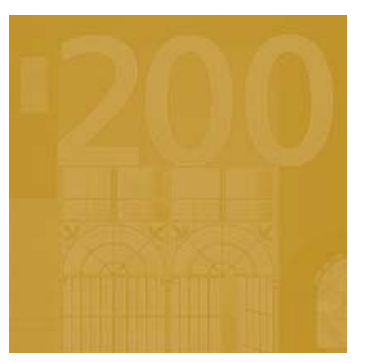

\title{
WORKING PAPER SERIES
}

NO 779 I JULY 2007

\author{
ECB/CEPR LABOUR \\ MARKET WORKSHOP ON \\ WAGE AND LABOUR \\ COST DYNAMICS
}

\section{ON-THE-JOB SEARCH AND THE CYCLICAL DYNAMICS OF THE LABOR MARKET '}

\author{
by Michael U. Krause ${ }^{2}$ \\ and Thomas A. Lubik ${ }^{3}$
}

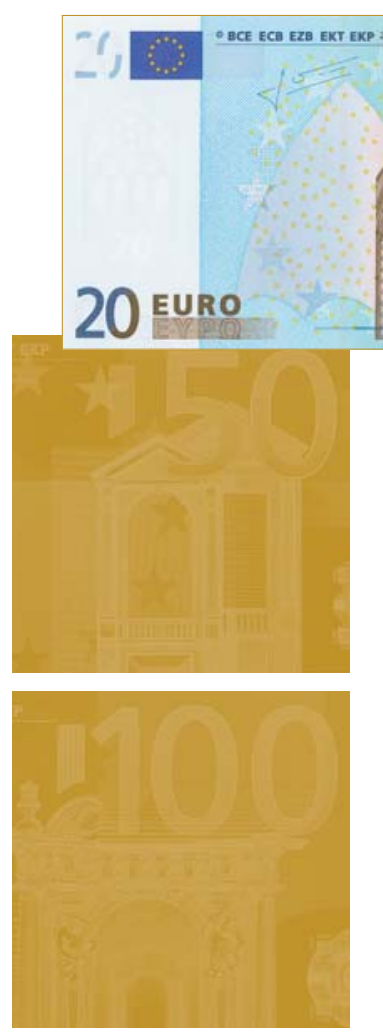

I Part of this research was conducted while the second author was visiting the Department of Economics at Tilburg University, whose hospitality is gratefully acknowledged. We thank Jan Boone, Winfried Koeniger, Jan van Ours, and in particular Robert Hussey and James Nason for comments and discussions. Special thanks go to Eva Nagypal for extensive comments on the 2004 version of this paper which helped improve the exposition. We also received useful comments from seminar participants at the 2004 Econometric Society Summer Meetings in Providence, the Society of Computational Economics Conference in Amsterdam, the Federal Reserve Bank of Atlanta, the EEA/ESEM meetings in Madrid, Deutsche Bundesbank, the SED 2005 meetings in Budapest, and Tilburg University. The views expressed in this paper are not necessarily those of the Federal Reserve Bank of Richmond, the Federal Reserve System or the Deutsche Bundesbank. 2 Economic Research Center, Deutsche Bundesbank, Wilhelm-Epstein-Str. I4, D-6043I Frankfurt, Germany, Tel.: +49(0)69 9566-2382, Fax: +49(0)69 9566-3082; e-mail: michael.u.krause@bundesbank.de 370 I East Byrd Street, Richmond,VA 2326I, USA;Tel.: + I 804 697-8246; e-mail: thomas.lubik@rich.frb.org 


\section{ECB/CEPR Labour Market Workshop on "Wage and Labour Cost Dynamics"}

This paper was presented at the ECB/CEPR Labour Market Workshop on "Wage and Labour Cost Dynamics", held on 14-15 December 2006 in Frankfurt am Main, Germany. The workshop was organized by Torben M Andersen (Universitet Aarhus and CEPR), Samuel Bentolila (CEMFI and CEPR), Ana Lamo (ECB) and Jarkko Turunen (ECB). The conference programme, including papers, can be found on the ECB's web site http://www.ecb.int/events/conferences/html/wage_and_labour.en.html

The views expressed in the paper are the author's own and do not necessarily reflect those of the Eurosystem.

\footnotetext{
(C) European Central Bank, 2007

Address

Kaiserstrasse 29

60311 Frankfurt am Main, Germany

Postal address

Postfach 160319

60066 Frankfurt am Main, Germany

Telephone

+496913440

Internet

http://www.ecb.int

Fax

+496913446000

Telex

411144 ecb d

All rights reserved.

Any reproduction, publication and reprint in the form of a different publication, whether printed or produced electronically, in whole or in part, is permitted only with the explicit written authorisation of the ECB or the author(s).

The views expressed in this paper do not necessarily reflect those of the European Central Bank.

The statement of purpose for the ECB Working Paper Series is available from the ECB website, http://www.ecb.int. 


\section{CONTENTS}

Abstract 4

Non-technical summary 5

1 Introduction 6

2 The empirical background 8

3 A business cycle model with on-the-job search 9

3.1 The labor market 10

3.2 Firms and product markets II

3.3 The aggregate household 12

3.4 Analytical results: job creation, search intensity, and wages $\quad 12$

4 Calibration and model solution I4

5 Model analysis $\quad 17$

5.1 Business cycle properties $\quad 17$

5.2 Impulse responses 18

5.3 Inspecting the mechanism with on-the-job search 19

5.3.1 Amplification $\quad 19$

5.3.2 Propagation 20

6 Discussion and robustness 21

6.1 The role of search intensity 2I

6.2 Endogenous search intensity of the unemployed

6.3 Wage setting arrangements and real wage rigidity

7 Relation to previous work

8 Conclusion

Appendix A Equation system 29

References

Tables and figures

European Central Bank Working Paper Series 


\begin{abstract}
We show how on-the-job search and the propagation of shocks to the economy are intricately linked. Rising search by employed workers in a boom amplifies the incentives of firms to post vacancies. In turn, more vacancies increases job search. By keeping job creation costs low for firms, on-the-job search greatly amplifies shocks. In our baseline calibration, this allows the model to generate fluctuations of unemployment, vacancies, and labor productivity whose magnitudes are close to the data, and leads output to be highly autocorrelated.
\end{abstract}

JEL CLASSIFICATION: E24, E32, J64

KEYWORDS:

Search and matching, job-to-job mobility, worker flows Beveridge curve, business cycle, propagation 


\section{Non-technical summary}

Models with search frictions in the labor market cannot replicate the cyclical dynamics of vacancies and unemployment, even though these are central elements of such models. In particular, under realistic calibrations, one can explain the volatilities of these variables only with implausibly large shocks. The reason is that in a boom wage pressures rise strongly when the number of unemployed job searchers falls. This in turn reduces the incentives for firms to open new vacancies. One solution to this problem is to assume real wage rigidity, as proposed by Hall (2005), such that labor demand stays high in a boom. However, this leaves open the question why such real wage rigidity should arise in the first place.

This paper proposes a simple solution to this puzzle, without the need to assume ad hoc real wage rigidity. We introduce the possibility that also employed workers search for jobs, so that vacancies can be filled with employees of other, less productive, firms that pay lower wages. In a boom, rising search activity by employed workers expands the pool of potential hires for firms, in addition to those searching from unemployment. This in turn reinforces the incentives to post vacancies by firms. But since all job searchers compete more strongly for the available vacancies, the wages of incumbent and newly hired workers rise much less than in the standard model.

To make this argument precise and to assess it quantitatively, we develop a standard general equilibrium business cycle model with search frictions in the labor market. Search on the job is motivated in a straightforward manner by the presence of two types of jobs, which differ in the return to working. Workers in jobs that pay lower wages search in order to gain employment in high-paying jobs. Wages are determined by Nash bargaining for each matched job-worker unit and continuously renegotiated. We calibrate the model to match salient long-run empirical features of job and worker flows, such as average separation and quit rates.

Our model can correctly predict the observed high volatility vacancies and unemployment, as well as of the vacancy-unemployment ratio. At the same time, the ratio of vacancies to unemployed and employed job seekers is substantially less volatile than in the standard model, which is key to wage dynamics. Thus wages are less volatile. In a boom, job-to-job flows increase substantially. But as search on the job rises, and firms' wage and hiring cost increases are muted, the incentive to create vacancies remains high. Employed workers' search activity responds strongly to a positive aggregate shock to take advantage of the increased availability of good employment opportunities. The resulting fall in unemployment is large. This is achieved even though productivity shocks are of plausible magnitude and wages are, a priori, fully flexible. The model also predicts a vacancy chain in that replacement hiring for bad jobs rises with quits.

This mechanism has important implications for business cycle analysis and monetary policy transmission. There is a powerful internal propagation mechanism, in that small aggregate impulses engender large and long-lasting responses of output and employment. This propagation is intricately linked with the complementarity between on-the-job search and vacancy creation. To the extent that labor costs include both wages and the costs of finding workers, on-the-job search delivers much lower volatility of real marginal costs in New Keynesian monetary models with monopolistic price setting. The sluggish response of wages and labor-market tightness that we find in the model will thus lead to more persistent movements in inflation. 


\section{Introduction}

Research starting with Hall (2005), Shimer (2005) and Costain and Reiter (2005) shows that the search and matching models along the lines of Mortensen and Pissarides (1994) can explain the cyclical dynamics of the labor market only by assuming implausibly large productivity shocks. For reasonable calibrations, the standard framework underpredicts the volatility of vacancies and unemployment. Both Hall and Shimer explore real wage rigidity as a solution to this shortcoming. With this element, firms' incentives to create new jobs in a boom are kept high since workers do not share the returns through bargaining. Hence, more vacancies are posted, and unemployment falls. This argument rests on the fact that the vacancy-unemployment ratio enters the wage equation, reflecting workers' outside options. Thus, when wages are not rigid, but continuously renegotiated, they are excessively volatile. ${ }^{1}$

We show in this paper that on-the-job search offers a resolution to this puzzle. In a boom, rising search activity by employed workers expands the pool of potential hires for firms, in addition to those searching from unemployment. As a consequence, the bargaining power of incumbent and newly hired workers rises by much less than would be implied by the standard vacancy-unemployment ratio. Wages exhibit less volatility than in the standard model.

To develop this argument, we present a general equilibrium business cycle model with labor market frictions and search by employed and unemployed workers. Search on the job is motivated in a straightforward manner by the presence of two types of jobs, which differ in terms of profitability and thus the returns to working. Workers in low-wage ('bad') jobs search in order to gain employment in high-wage ('good') jobs. Good job vacancies can be matched with employed and unemployed job seekers, whereas firms in the bad job sector only hire unemployed workers. Wages are determined by Nash bargaining for each matched job-worker unit and continuously renegotiated. We calibrate the model to match salient long-run features of job and worker flows.

Our model can correctly predict the observed volatility of the vacancy-unemployment ratio. At the same time, the ratio of vacancies to unemployed and employed job seekers is substantially less volatile, which is key to wage dynamics. Employed workers' search activity responds strongly to a positive aggregate shock to take advantage of the increased availability of good employment opportunities. Job-to-job flows increase substantially. But as search on the job rises, and wage and hiring cost increases are muted, the incentive to

\footnotetext{
${ }^{1}$ Hagedorn and Manovskii (2005), Fujita and Ramey (2005), and Rotemberg (2006), among others, explore alternative mechanisms.
} 
create vacancies remains high. The corresponding fall in unemployment is large. This is achieved even though productivity shocks are of plausible magnitude and wages are, a priori, fully flexible. Moreover, on-the-job search yields a powerful internal propagation mechanism in that small aggregate impulses engender large and long-lasting responses of output and employment. We show that this propagation is intricately linked with the mechanism that keeps job creation high.

Important for the ability of the model to match the data is the interaction of two features: the endogeneity of on-the-job search and vacancy creation. The former maintains the incentives to create good jobs in a boom, since the likelihood of filling a vacancy remains large, in spite of falling unemployment. The increasing availability of good vacancies, raises employed workers' search effort. Without either element, the response of job-to-job transitions and the propagation of shocks on output would be much weaker. This complementarity explains the prolonged effect of shocks. Furthermore, not only are more new jobs created, but the job composition shifts towards more productive jobs, which raises aggregate output.

The closest precursors of our model with on-the-job search are the contributions by Pissarides (1994) and Mortensen (1994). The former studies a deterministic, continuous-time model and qualitatively discusses possible adjustment dynamics. It shares the heterogeneity in job types employed in this paper. The latter conducts a simulation of a stochastic version of the Mortensen and Pissarides (1994) model. Mortensen shows that on-the-job search helps explain the negative correlation between job creation and destruction rates. In both papers, employed search varies through adjustments in the number of searchers, rather than the intensity of search. Finally, the two papers have exogenous interest rates and prices, shutting down general equilibrium effects, which affect the dynamics of vacancies and unemployment. Neither of the papers considers these dynamics quantitatively. Nagypal (2005) considers the implications of on-the-job search motivated by subjective perceptions of job quality by workers. While her analysis does not include aggregate propagation effects, she also finds large differences in vacancies and unemployment in a comparative statics exercise.

The paper proceeds as follows. The next section gives a brief discussion of the relevant evidence on the dynamic behavior of the labor market, in particular the quit rate. Section 3 lays out the model and characterizes the steady state. Section 4 gives the calibration details. The results of the dynamic simulation of the model are presented in section 5, while section 6 contains further discussion and section 7 relates the findings to the literature. Section 8 concludes. The log-linearized model and remarks on the solution procedure can be found in the Appendix. 


\section{The Empirical Background}

This section documents the cyclical behavior of vacancies, unemployment, and labor market tightness for the U.S. labor market and their relation to productivity, output, employment, and real wages. While we use labor market data from 1948 until 2003, some other series cover only a shorter period. In particular, the time series on average hourly earnings which is only available from 1964 on and which we use as our measure of the real wage (deflated by the CPI). All series are available from the website of the U.S. Bureau of Labor Statistics (www.bls.gov), except the series on quits, which has been compiled from the Employment and Earnings publication of the BLS. This series, however, is only available up to 1982, when it was discontinued. Vacancies are constructed from the BLS index of help-wanted advertisements. All variables are quarterly and, where appropriate, detrended using the HP-filter, with the smoothing parameter set to 1600.

The dynamics of vacancies and unemployment follow a familiar pattern. Figure 1 shows vacancies that are highly procyclical whereas unemployment is strongly countercyclical; that is, the two variables exhibit a Beveridge curve with a contemporaneous correlation of -0.95 . This pattern implies that a measure of labor market tightness, the vacancyunemployment ratio, is also highly procyclical. Table 1 presents the standard deviations and cross-correlations of the variables of interest. Real wages are procyclical, the degree of which depends on the time period considered. ${ }^{2}$ Particularly the 1970s feature a highly procyclical real wage, while from the 1980s on it appears almost acyclical. In fact, for the full sample, the correlation between output and real wages is 0.57, whereas from 1982 onward it is merely 0.26 . For consistency with the theoretical model, we take output per worker as a measure of labor productivity, which has a correlation with output of $0.69 .^{3}$

One of the central variables for the argument considered in this paper is the rate of job-to-job mobility and quits, which we consider to be the outcome of on-the-job search activity. Two data sets have become available recently, but they only cover relatively short periods of time. The Job Openings and Labour Turnover Survey (JOLTS) by the U.S. Bureau of Labor Statistics was begun in December 2000. This period essentially covers only one mild downturn. Since 1994, the Current Population Survey uses a "dependent interviewing" technique which allows construction of detailed worker flow series. This series

\footnotetext{
${ }^{2}$ These results are not reported, but available from the authors.

${ }^{3}$ Output per hour has a correlation of 0.54 with output.
} 
thus comprises the protracted boom of the 1990s as well as the subsequent downturn. This dataset does not allow us, however, to infer unconditional time series properties of the data, but it is at least useful in providing long-run averages.

A long time series on worker mobility and quits is contained in the BLS labor turnover series for the manufacturing sector from 1926 to 1981, which we use from 1948 on. We follow Blanchard and Diamond (1989) by making two adjustments based more recent numbers. First, quit rates in manufacturing tend to be lower than in the entire economy and therefore need to be adjusted upwards. We use Fallick and Fleischman's (2004) finding based on the CPS data. They find an economy-wide average monthly quit rate of $2.6 \%$. Some caution may be mandated since the data cover only one upswing and one mild downturn. A long-run average which includes a severe contraction might yield somewhat lower rates. Secondly, not all quits are job-to-job flows. Fallick and Fleischman (2004) suggest that job-to-job quits are about half of total quits, while Blanchard and Diamond (1989) postulate 40 percent.

The standard deviation of the adjusted quit series can be found Table 1, based on the sample up to the end of 1981. It is worth noting that the quit rate is eight times as volatile as GDP and about 50 percent more volatile than unemployment. ${ }^{4}$ Figure 1 shows that the quit rate appears to comove with the vacancy index, especially between about 1955 and 1975. In fact, the detrended series of vacancies and the quit rate for the whole period have a correlation of 0.94. Increased availability of data from the CPS and JOLTS will allow to test whether the volatilities short-run relationships between quits, unemployment, and vacancies have significantly changed since $1982 .^{5}$

\section{A Business Cycle Model with On-the-Job Search}

Time is discrete and infinite, and the economy is populated by a representative household, homogeneous workers and heterogeneous firms. There are two classes of firms, labeled 'good' and 'bad', which differ in their costs of creating new jobs. In the presence of labor market frictions, these costs generate rents which give rise to differences across jobs in the value of being employed. ${ }^{6}$ These differentials motivate workers in low-wage jobs to search for employment in high-wage jobs. All workers in low-wage jobs search on the job. The intensity of their search is endogenous. Unemployed workers direct their search to either good jobs or bad jobs, according to the returns to search. Workers in good jobs have no

\footnotetext{
${ }^{4}$ See Petrongolo and Pissarides (2000) for evidence on the relative magnitudes of different quit flows.

${ }^{5}$ See Shimer (2005) for most recent evidence.

${ }^{6}$ In this respect, the model is similar to Pissarides (1994) and Acemoglu (2001). The key elements of the model are the heterogeneity of jobs and the endogeneity of search intensity by employed workers.
} 
incentive to search as it is costly and does not offer any improvements over their current returns to employment. We first characterize labor and product markets, and the aggregate household problem. We then discuss the optimal choices by firms and workers in this environment.

\subsection{The Labor Market}

The process of matching workers and firms is subject to frictions, represented by a matching function, which gives the number of per period matches of job searchers and vacancies. The matching function is constant returns to scale and homogeneous of degree one. It is the same for both job types and searchers. ${ }^{7}$ For good jobs, the total number of per-period new matches between vacancies and searching workers is given by:

$$
m_{t}^{g}=m\left(v_{t}^{g}, u_{t}^{g}+e_{t}\right)
$$

where $v_{t}^{g}$ is the measure of good job vacancies, $u_{t}^{g}$ the measure of unemployed workers searching for good jobs, and $e_{t}=s_{t} n_{t}^{b}$ is the measure of efficiency units of search by employed job seekers $n_{t}^{b}$, who search with intensity $s_{t}$. Unemployed job seekers are assumed to search with fixed search intensity (equal to one) $)^{8}$. For bad jobs, the number of matches between vacancies and unemployed workers is:

$$
m_{t}^{b}=m\left(v_{t}^{b}, u_{t}^{b}\right)
$$

Note that unemployed workers search in distinct pools for jobs, and have to make a decision as to which type of job they devote their search effort. Worker mobility implies that the returns to search for either job type are equalized.

Central to the choices of firms and workers are the probabilities of finding a match for the participants in the matching market. Define $\theta_{t}^{g}=v_{t}^{g} /\left(u_{t}^{g}+e_{t}\right)$ and $\theta_{t}^{b}=v_{t}^{b} / u_{t}^{b}$ as measures of labor market tightness in the matching markets for good jobs and bad jobs, respectively. Vacancies are filled with the corresponding probabilities $q_{t}^{g} \equiv m_{t}^{g} / v_{t}^{g}=m\left(1,1 / \theta_{t}^{g}\right)$ and $q_{t}^{b} \equiv m_{t}^{b} / v_{t}^{b}=m\left(1,1 / \theta_{t}^{b}\right)$. For searching workers, the probabilities of finding a good or bad vacancy are given by $p_{t}^{g} \equiv m_{t}^{g} /\left(u_{t}^{g}+e_{t}\right)=m\left(\theta_{t}^{g}, 1\right)$ and $p_{t}^{b} \equiv m_{t}^{b} / u_{t}^{b}=m\left(\theta_{t}^{b}, 1\right)$. An employed worker's probability of being matched with a good job is $s_{t} p_{t}^{g}$ with $p_{t}^{g}$ taken as

\footnotetext{
${ }^{7}$ This assumption is usually based on empirical findings, such as those by Blanchard and Diamond (1990). Note, however, that these estimates ignore the presence of job-to-job flows. For a thorough discussion of the potential biases see Petrongolo and Pissarides (2001).

${ }^{8}$ This assumption will be relaxed below, and shown to have no substantive implications for the results.
} 
given by the worker. Note that employed job seekers and unemployed job seekers cause congestion for each other in the market for good jobs. ${ }^{9}$

Finally, the evolution of employment in good and bad jobs is governed by the equations:

$$
\begin{aligned}
n_{t+1}^{g} & =(1-\rho)\left[n_{t}^{g}+m_{t}^{g}\right], \\
n_{t+1}^{b} & =(1-\rho)\left[n_{t}^{b}+m_{t}^{b}-s_{t} p_{t}^{g} n_{t}^{b}\right],
\end{aligned}
$$

where $\rho$ is the probability of matches breaking up, which is exogenous and identical for both types of jobs. ${ }^{10}$ It comprises both job destruction events and separations of workers for reasons other than quits to another employer. The last term in the second equation can also be expressed as $s_{t} p_{t}^{g} n_{t}^{b}=e_{t} /\left(u_{t}^{g}+e_{t}\right) m_{t}^{g}$, which is the fraction of new good matches that meet with employed searchers. Aggregate unemployment equals $u_{t}=u_{t}^{g}+u_{t}^{b}=1-n_{t}^{g}-n_{t}^{b}=1-n_{t}$.

For wage bargaining, we assume that a worker and a firm split in fixed proportions the joint surplus that their match generates. The surplus of job type $i$ is given by $S_{t}^{i}=$ $J_{t}^{i}-V_{t}^{i}+W_{t}^{i}-U_{t}$, where $J_{t}^{i}$ is the value of a filled job for firms, $V_{t}^{i}$ the value of a vacancy, $W_{t}^{i}$ is the return of working to a worker, and $U_{t}^{i}$ is the value of unemployment. The wage has to be such that workers obtain a share $W_{t}^{i}-U_{t}=\eta S_{t}^{i}$, with bargaining weight $0<\eta<1$. Firms receive the remainder $J_{t}^{i}=(1-\eta) S_{t}^{i}$. Wages are determined by taking the search intensity of workers as given, while search intensity itself is chosen by workers taking as given the current wage. Contracts are renegotiated each period.

\subsection{Firms and Product Markets}

The cost of creating a job is represented by a flow cost of posting a vacancy, $c^{g}$ for good firms, and $c^{b}$ for bad firms, where $c^{g}>c^{b}$. Production of a (representative) firm of type $i=g, b$ is given by the constant returns to scale technologies:

$$
y_{i t}=A_{t} n_{t}^{i}
$$

where $A_{t}$ is aggregate productivity and $n_{t}^{i}$ is employment in sector $i$. Output of good and bad firms is combined in a final goods sector according to a the aggregator:

$$
y_{t}=y_{b t}^{\alpha} y_{g t}^{1-\alpha} .
$$

\footnotetext{
${ }^{9}$ This observation is consistent with empirical evidence, see for example Burgess (1995), but also the discussion in Petrongolo and Pissarides (2001). In Pissarides' (1994) model with on-the-job search, workers cannot direct their search and are randomly matched across good and bad vacancies.

${ }^{10}$ Allowing for differing job destruction rates for good jobs would not change the basic mechanism of the model.
} 
The two intermediate goods, $y_{g t}$ and $y_{b t}$, are sold at competitively determined prices, $P_{g t}=$ $(1-\alpha)\left(y_{g t} / y_{t}\right)^{-1}$ and $P_{b t}=\alpha\left(y_{b t} / y_{t}\right)^{-1}$. We have chosen the price of aggregate output as the numeraire. In the model, both types of jobs coexist in equilibrium. ${ }^{11}$

\subsection{The Aggregate Household}

We use a representative household to construct the discount factor that governs intertemporal decisions of workers and firms. We follow Merz (1995) and others in assuming that workers are members of a large family which pools income and then redistributes it equally to all members. The family ensures that all workers, employed and unemployed, participate in the labor market. Thus the optimization problem of a representative household is:

$$
\max _{\left\{c_{t}\right\}_{t=0}^{\infty}} E_{0} \sum_{t=0}^{\infty} \beta^{t} \frac{c_{t}^{1-\tau}-1}{1-\tau},
$$

subject to the aggregate resource constraint:

$$
c_{t}=y_{t}-h_{t}
$$

where $0<\beta<1$ is the household's discount factor, and $\tau>0$ is the inverse of the intertemporal elasticity of substitution. $c_{t}$ is consumption, $y_{t}$ is aggregate production and $h_{t}=c^{g} v_{t}^{g}+c^{b} v_{t}^{b}$ are the aggregate hiring (or job creation) costs incurred by firms. From the household's problem we can construct the implied stochastic discount factor $\beta_{t+1}=$ $\beta c_{t+1}^{-\tau} / c_{t}^{-\tau}$, which firms and workers use to evaluate their activities.

\subsection{Analytical Results: Job Creation, Search Intensity, and Wages}

The optimal choices by firms and workers are governed by asset values. While the values for good jobs and their workers are the same as in the standard search and matching model, the values for bad jobs differ in the presence of on-the-job search. The asset values of jobs filled with a worker are given by the Bellman equations:

$$
\begin{aligned}
J_{t}^{g} & =P_{g t} A_{t}-w_{t}^{g}+E_{t} \beta_{t+1}\left[(1-\rho) J_{t+1}^{g}+\rho V_{t+1}^{g}\right], \\
J_{t}^{b} & =P_{b t} A_{t}-w_{t}^{b}+E_{t} \beta_{t+1}\left[(1-\rho)\left(1-s_{t} p_{t}^{g}\right) J_{t+1}^{b}+\left(\rho+(1-\rho) s_{t} p_{t}^{g}\right) V_{t+1}^{b}\right] .
\end{aligned}
$$

$w_{t}^{i}, i=g, b$ are the wages paid, $E_{t}$ is the expectation operator conditional on the information set at time $t$. Jobs survive into the next period with probability $(1-\rho)$, and are destroyed

\footnotetext{
${ }^{11} \mathrm{~A}$ similar product market structure is used by Acemoglu (2001). It can be interpreted as representing differences across industries or differences across firms within industries. Evidence by Parent (2000), among others, indicates that a large fraction of job-to-job transitions are within industries. This is suggestive of intra-industry differences of jobs motivating worker mobility. Additional evidence comes from Albaek and Sorensen (1998), who find that flows of workers in upturns typically are from small firms to large firms.
} 
otherwise. Bad jobs face the additional risk of workers leaving to good jobs. A higher search intensity by a worker reduces the likelihood of the job remaining matched in the next period.

The value $V_{t}^{i}$ of a vacancy for either good or bad jobs, $i=g, b$, is:

$$
V_{t}^{i}=-c^{i}+E_{t} \beta_{t+1}\left[(1-\rho) q_{t}^{i} J_{t+1}^{i}+\left(1-(1-\rho) q_{t}^{i}\right) V_{t+1}^{i}\right]
$$

A vacancy is filled and produces in the next period with probability $q_{t}^{i}(1-\rho)$. Free entry implies that the values of vacancies are driven to zero at any point in time, i.e., $V_{t}^{g}=V_{t}^{b}=0$, for all $t$. Solving the asset equations for vacancies yields two job creation conditions, which are central to the analysis:

$$
\begin{aligned}
& \frac{c^{g}}{q_{t}^{g}}=(1-\rho) E_{t} \beta_{t} J_{t+1}^{g}, \\
& \frac{c^{b}}{q_{t}^{b}}=(1-\rho) E_{t} \beta_{t} J_{t+1}^{b} .
\end{aligned}
$$

The equations relate the expected cost of a posted vacancy to the expected benefit. To understand why this condition must hold, consider the case where $c^{g} / q_{t}^{g}<(1-\rho) E_{t} \beta_{t} J_{t+1}^{g}$. It is then profitable to post additional vacancies, $v_{t}^{g}$, which leads to a rise in labor market tightness $\theta_{t}^{g}$ and thus a fall in $q_{t}^{g}=q\left(\theta_{t}^{g}\right)$. Vacancies rise until no ex-ante returns remain.

Turning to workers, the asset values of employment in good and bad jobs are, respectively:

$$
\begin{gathered}
W_{t}^{g}=w_{t}^{g}+E_{t} \beta_{t+1}\left[(1-\rho) W_{t+1}^{g}+\rho U_{t+1}\right] \\
W_{t}^{b}=\max _{s_{t}}\left(w_{t}^{b}-k\left(s_{t}\right)+E_{t} \beta_{t+1}\left[(1-\rho)\left(1-s_{t} p_{t}^{g}\right) W_{t+1}^{b}+(1-\rho) s_{t} p_{t}^{g} W_{t+1}^{g}+\rho U_{t+1}\right]\right) .
\end{gathered}
$$

$k\left(s_{t}\right)$ denotes the strictly convex cost of search intensity $s_{t}$, with $k(0)=0, k^{\prime}>0$, and $k^{\prime \prime}>0$. The higher the search intensity, the more likely the worker is matched with a good job. Convexity of the effort function guarantees uniqueness of the optimal search effort. For $s_{t}=0$, the worker either stays on the job or returns to unemployment after an exogenous separation. Search intensity is chosen by the worker taking the wage as given, on grounds that firms cannot directly observe the search effort of workers. However, firms anticipate the optimal choice that workers will make in equilibrium. The optimal search intensity is:

$$
k^{\prime}\left(s_{t}\right)=\frac{\eta}{1-\eta} p_{t}^{g}\left(\frac{c^{g}}{q_{t}^{g}}-\frac{c^{b}}{q_{t}^{b}}\right),
$$

where we used the fact that $c^{i} / q_{t}^{i}=(1-\rho) E_{t} \beta_{t} J_{t+1}^{i}=(1-\rho) E_{t} \beta_{t}\left[W_{t+1}^{i}-U_{t+1}\right](1-\eta) / \eta$ from bargaining. Thus, search intensity rises with the probability of finding a good job, 
and with the difference between the value of good and bad jobs. If $c^{g} / q_{t}^{g} \leq c^{b} / q_{t}^{b}$ no search would take place on bad jobs. The factor $\eta /(1-\eta)$ reflects the fact that workers obtain only a share of the value of a job. ${ }^{12}$

The asset values of unemployed search for jobs of type $i=g, b$ are

$$
U_{t}^{i}=z+E_{t} \beta_{t+1}\left[p_{t}^{i}(1-\rho) W_{t+1}^{i}+\left(1-p_{t}^{i}(1-\rho)\right) U_{t+1}^{i}\right] .
$$

From worker mobility, we know that $U_{t}^{g}=U_{t}^{b}=U_{t}$, for all $t$. Setting the asset values equal, and using the bargaining equations yields $p_{t}^{g}(1-\rho) E_{t} \beta_{t} J_{t+1}^{g}=p_{t}^{b}(1-\rho) E_{t} \beta_{t} J_{t+1}^{b}$. Inserting the job creation condition gives:

$$
p_{t}^{g} \frac{c^{g}}{q_{t}^{g}}=p_{t}^{b} \frac{c^{b}}{q_{t}^{b}} \quad \Longleftrightarrow \quad \theta_{t}^{g} c^{g}=\theta_{t}^{b} c^{b} .
$$

Thus the relative labor market tightness for both types of jobs are exactly proportional to the relative costs of job creation.

Finally, the wages paid in good and bad jobs are, respectively,

$$
w_{t}^{g}=\eta P_{g t} A_{t}+(1-\eta) z+\eta \theta_{t}^{g} c^{g}
$$

and

$$
w_{t}^{b}=\eta P_{b t} A_{t}+(1-\eta)\left(z+k\left(s_{t}\right)\right)+\eta\left(\left(1-s_{t}\right) \theta_{t}^{g} c^{g}\right) .
$$

The equations are derived from the bargaining relationship $(1-\eta)\left(W_{t}^{i}-U_{t}\right)=\eta J_{t}^{i}$, using the respective asset equations and the job creation conditions. ${ }^{13}$ The second equation makes use of equation (16). The wage compensates the worker for the incurred search cost $k\left(s_{t}\right)$ and compensates the firm for the increased likelihood of separation due to the workers search effort $s_{t}$.

\section{Calibration and Model Solution}

We proceed by linearizing the equation system around the non-stochastic steady state. The resulting linear rational expectations model is then solved by the method described in Sims

\footnotetext{
${ }^{12}$ There is no role of the wage for reducing the likelihood of workers quitting, because of the timing structure of the model and the nature of bargaining. Wages are continuously renegotiated so that currently paid wages have no implications for wages paid next period, which will be newly negotiated. But next period's payments are what motivates worker search this period. If firms could commit to wages for more than a period, then adjusting today's wage would have an effect on search intensity and thus quitting. We exclude this possibility. This also allows us to determine the wage as an outcome to Nash bargaining, because the bargaining set is convex. The need to determine the wage as the outcome of bargaining with alternating offers thus does not arise. See Shimer (2006) for a careful discussion.

${ }^{13} \mathrm{We}$ assume at this stage that wages in previous jobs are not part of the outside options of a worker. Alternative assumptions on the wage determination of job switchers is elaborated upon in Section 5 .
} 
(2002). To evaluate the cyclical properties of the model we assign numerical values to the structural parameters. The calibration is somewhat more complicated than in the standard model as aggregate statistics can not easily be matched with corresponding model statistics. Moreover, since pertinent information is available for some parameters, we have to compute these indirectly from the steady-state values of quantifiable endogenous variables. The calibration is summarized in Table 2.

We choose a separation rate of $\rho=0.1$. Following the argument in Den Haan, Ramey, and Watson (2000), this value captures both exogenous job destruction as well as quits into unemployment or movements out of the labor force. The unemployment rate is set to $12 \%$, i.e., $u=0.12$. It is chosen higher than that commonly observed in the data to take into account workers that are only loosely attached to the labor force, such as discouraged workers or workers engaging in home production. Once the opportunity arises, these (potential) workers participate in the matching market. ${ }^{14}$

We set the steady-state job-to-job transition rate to 0.06 . In our model, this corresponds to the term $e p_{g} / n$, i.e. the number of workers in bad jobs who move on to good jobs relative to total employment. This number stems from the data on job-to-job quits as reported above. When combined with the dynamics of employment, this implies a ratio of job-to-job movements to total hires of $54 \%$, which is at the high end of the empirically plausible range.

For the matching function, we choose a Cobb-Douglas form that is identical in both sectors, so that $m_{g}=M_{g} v_{g}^{1-\mu}\left(u_{g}+e\right)^{\mu}$ and $m_{b}=M_{b} v_{g}^{1-\mu} u_{b}^{\mu}$. Similarly to the literature, the elasticity parameter is calibrated as $\mu=0.4 .{ }^{15}$ The level parameters $M_{g}, M_{b}$ are computed to imply an average firm matching probability of 0.7 , which is a commonly used value in the literature. This leads to $M_{g}=0.6$ and $M_{b}=0.6$. The corresponding steady state sectoral matching rates, that is, the probability that a firm in the good or bad sector finds an employee, are 0.77 and 0.63 , respectively.

Job heterogeneity is generated by differences in the job creation costs $c_{g}>c_{b}$. Crucial as these parameters are, it is also not trivial to pin them down. We let our choice be motivated by the following considerations. First, job creation costs consist of costs for recruitment, training, and unused capital, which are likely to be proportional to the capital intensity. In fact, Acemoglu (2001) links creation costs to capital intensities in service and manufacturing sectors. We thus impose that job creation costs for good firms are four times as large as for

\footnotetext{
${ }^{14}$ This argument is based on Blanchard and Diamond (1990).

${ }^{15}$ Empirical estimates of this elasticity parameter are biased when there is on-the-job search (see Petrongolo and Pissarides, 2001, for the estimation). We are aware of no empirical study of the matching function that takes on-the-job search into account.
} 
bad firms, which is in the order of magnitude of the difference between the capital intensity of average high-wage and low-wage jobs. Secondly, even though job creation costs can be treated as scale parameters, they should not be out of line with the general steady state implications of the model. Specifically, they cannot be so large as to substantially reduce aggregate GDP below production. Setting $c_{g}=0.16$ and $c_{b}=0.04$ results in $5 \%$ of output used in job creation activities and obeys the first criterion. Furthermore, we impose that sectoral prices are roughly equal in steady state which implies a share $\alpha=0.4$ of production derived from bad jobs. Together with the differential in job creation costs, this implies that wages are higher in good jobs.

The costs of searching on the job are assumed to be strictly increasing and convex in the search intensity. We use $k(s)=\kappa s^{\sigma}$, where $\kappa>0, \sigma>1$. In our benchmark calibration we choose $\sigma=1.5$. We regard highly elastic search as the most plausible case. First, there may be increasing returns to search as argued by Rotemberg (2006). Secondly, the model tries to explain data generated by search at both the intensive and extensive margins. ${ }^{16}$ Note also that Merz (1995) chooses a value of one. Since this is one of our main parameters of interest, we will present and discuss the implications of variations in the search elasticity. The scale parameter $\kappa$ is not chosen independently, but is computed implicitly to be consistent with the calibrated steady state. We find $\kappa=0.04$.

The parameters describing the household are standard. We choose a coefficient of relative risk aversion $\tau=1$, and a discount factor $\beta=0.98$. The worker's share in the surplus of the match is $\eta=0.5$. There is no independent information available on the utility value of household production $z$. Reverse calibration of the unemployment rate, however, implies that $z=0.39$, which is below wages in both sectors.

Finally, we need to calibrate the shock process. The (logarithm of the) aggregate productivity shock is assumed to follow an $\operatorname{AR}(1)$ process with coefficient $\rho_{A}=0.90$. As is common in the literature we choose an innovation variance such that the baseline model's predictions match the standard deviation of U.S. GDP, which is $1.62 \%$. While this is not a robust procedure, it is not essential for our approach since we do not evaluate the model along this dimension. What matters are the relative volatilities of the variables of interest. Consequently, the standard deviation of technology is set to $\sigma_{\varepsilon}=0.0049$.

Based on this calibration, we find that in the non-stochastic steady state equilibrium about $30 \%$ of jobs are bad, and that search intensity $s$ is about one third. In other words, $10 \%$ of the labor force are effectively searching on the job. A relatively low number of

\footnotetext{
${ }^{16}$ Christensen et al, who estimate a search model with intensive and extensive search on the job, find a search elasticity of 2 .
} 
unemployed workers look for good jobs $(1.3 \%)$, while the remainder of the unemployed $(10.7 \%)$ search for bad jobs. This is the result of an endogenous response of the unemployed to the competition for good jobs that they face with employed seekers. Vacancies relative to the labor force (which is normalized to one) are 7.5 percent for good jobs, and 15.6 percent for bad jobs.

The resulting match probabilities for firms are $q_{g}=0.75$ and $q_{b}=0.57$, while for workers the probabilities to be matched with a good or bad job are $p_{g}=0.43$ and $p_{b}=0.67$. Similarly, the flow of new good matches per period is 0.057 and for new bad matches 0.092 . The larger amount of bad matches reflects the fact that the workers moving from bad to good jobs are replaced at the industry level. ${ }^{17}$ We finally note that wages for good jobs are slightly higher than for bad jobs, the difference being roughly $4 \%$.

\section{Model Analysis}

We first discuss the business cycle statistics generated from a simulation of the model, followed by a characterization of the economy's response to a productivity shock. We then analyse in detail the sources of the propagation and amplification mechanism at work in the model.

\subsection{Business Cycle Properties}

We report labor market variables of interest in Table 3. Since the variance of the technology shock was calibrated to match the standard deviation of U.S. GDP we only evaluate the model's predictions based on relative volatilities. We find that, in general, the variables in the model are only slightly less volatile than in the data, in particular, vacancies, unemployment, and labor market tightness. Most notable, however, is the large discrepancy between the standard measure of tightness $\theta=v / u$ and our alternative measure inclusive of on-the-job seekers, $\widetilde{\theta}=v /(u+e)$. This suggests that on-the-job search has a significant effect on the model's propagation mechanism, when compared to the standard framework, as labor market tightness is the driving force behind firms' vacancy posting decisions and wage setting outcomes.

To wit, the aggregate wage is substantially less volatile than in the data which we interpret as endogenously generated inertia in the absence of any ad-hoc wage stickiness mechanism. Similarly, the volatility of the quit rate comes very close to what is observed

\footnotetext{
${ }^{17}$ The flows in the bad job sector can be interpreted as either reflecting replacement hiring at the firm level, or as job destruction in some firms, while others expand, holding total industry employment steady.
} 
in the data, which is a result of the highly responsive search intensity. The supply of additional searchers holds the ratio of vacancies to unemployment and employed search relatively stable. At the same time, it keeps the incentives high for firms to post vacancies.

The simulation also yields strong predictions with respect to contemporaneous correlations. First and foremost is the Beveridge curve, the negative correlation of unemployment and vacancies over the business cycle. In U.S. data this correlation is -0.95 , which are able to replicate fairly closely. ${ }^{18}$ We also match the negative comovement of unemployment with all other aggregate variables of interest. For instance, the unemployment rate is highly negatively, though not perfectly, correlated with the job-to-job transition rate. When an adverse technology shock raises unemployment, search intensity falls due to a declining job finding probability. Workers are therefore less likely to engage in on-the-job search so that relatively fewer workers in bad jobs move on to better ones. Interestingly, our two measures of labor market tightness are perfectly correlated on account of the strong comovement of search intensity with GDP. We also note the very high procylicality of job-to-job quits in terms of the correlation with output. A noteworthy exception is the high correlation of wages and on the job search in the model, in contrast to the data.

\section{$5.2 \quad$ Impulse Responses}

We illustrate the influence of on-the-job search on the model dynamics by using the impulse responses reported in Figures 2 and 3. Consider a positive, one percent shock to productivity. On impact, aggregate output rises with productivity, followed by a protracted humpshaped increase until three quarters after the shock. At the same time, vacancies and labor market tightness for both job types rise. As the probability of finding good jobs is now higher, search intensity, and with it the effective amount of on-the-job searchers, $e$, jumps up. Vacancies for bad jobs rise by even more than for good jobs, because firms anticipate the future flows of workers to better jobs, which will have to be replaced. Unemployment does not fall until the second period, as it takes time for new matches to be formed. The unemployed redirect their search activity to low quality jobs, as they react to the increased competition with employed searchers.

In the periods after the shock, differential effects unfold along various dimensions. While good vacancies begin to fall from their new higher level, bad vacancies further increase. This is due to the fact that as employment rises for both job types, more workers leave bad jobs, requiring rising replacement hiring. Overall, the hiring rate rises for several more quarters.

\footnotetext{
${ }^{18}$ For their model, Mortensen and Pissarides (1994) report a correlation of only -0.26 . See also the interesting discussion in Shimer (2005).
} 
Furthermore, search intensity continues to rise because the fall in unemployment increases the chances of the employed to be matched with good jobs even more. Employment in the good sector rises because the inflow of new workers exceeds the outflow from job destruction.

Even though the standard measure of labor market tightness $\theta=v / u$ is highly volatile, wages rise by much less than without on-the-job search. The reason is that the measures of labor market tightness relevant for the workers' outside options that enter wage bargaining, are substantially less volatile, as can be seen in Figure 3. The wage in bad jobs rises by less, however, because of higher search intensity. While search has a positive impact on the present value of the match for workers, it reduces the value of the match to firms.

We see from the impulse responses that changes in productivity have persistent effects, indicating that search on the job adds substantial propagation to the model. Similarly, employment has a hump-shaped response. This is not caused per se by the heterogeneity of jobs in the economy. Analysis of the model without employed search, as in Krause and Lubik (2006), show that the impulse responses of that model are very similar to those of a standard one-sector model, such as those by Andolfatto (1996) or Merz (1995).

\subsection{Inspecting the Mechanism with On-the-Job Search}

This sections digs deeper into the mechanism that generates the results of the model. We argue that on-the-job search modifies the standard model both in terms of amplification and propagation of productivity shocks in a qualitatively significant manner.

\subsubsection{Amplification}

Amplification is most closely tied to the job creation condition (12) and the optimal search condition (14). Rewrite the job creation condition for good jobs using the parameterization of the matching function:

$$
\frac{c^{g}}{m}\left(\theta_{t}^{g}\right)^{\mu}=(1-\rho) E_{t} \beta_{t} J_{t+1}^{g} .
$$

Our thought experiment is as follows. Suppose the expression on the right hand side increases due to higher future productivity of jobs. This will cause firms to post more vacancies until equality is restored. However, there is a contemporaneous effect of higher vacancy creation to employed job search, which further feeds back to vacancy creation.

The feedback between on-the-job search and vacancies can be deduced from inspection of the optimal search condition. Using the sectoral arbitrage condition for unemployed 
searchers and the functional form of the matching function we have:

$$
k^{\prime}\left(s_{t}\right)=\frac{\eta}{1-\eta} c^{g}\left[1-\left(\frac{c^{b}}{c^{g}}\right)^{1-\mu}\right] \theta_{t}^{g} .
$$

Since $c^{g}>c^{b}$ the term in squared brackets is between zero and one. Movements in labor market tightness in the good jobs sector explain all variation in search intensity. An increase in $s_{t}$ in turn affects $\theta_{t}^{g}$ as seen from the definition:

$$
\theta_{t}^{g}=\frac{v_{t}^{g}}{u_{t}^{g}+s_{t} n_{t}^{b}}
$$

where we make use of $e_{t}=s_{t} n_{t}^{b}$. Thus, for any increase in $\theta_{t}^{g}$ mandated by the job creation condition, higher vacancy creation increases the amount of job search as implied by the optimal search condition. This lowers tightness, and vacancies will therefore have to increase further to meet the job creation condition. Alternatively, for a given increase in labor market tightness, any increase in vacancies posted in the good sector further increases in the search intensity of employed job seekers, by virtue of $\sigma>1$. This in turn induces firms to post more vacancies. The process ends due to the decreasing returns inherent in the cost of search.

There is a second feedback effect, which works through the search behavior of the unemployed. On impact of an aggregate shock to productivity, which affects both types of jobs, unemployed workers redirect their search effort to the bad job sector. The reason is the increasing competition with employed searchers for good jobs. Search for low quality jobs will be relatively more attractive. Furthermore, as those who quit for good jobs will have to be replaced, additional vacancies are posted.

\subsubsection{Propagation}

The propagation mechanism of on-the-job search can be explained through the evolution of unemployment. In the standard model, lower unemployment reduces firms' incentives to post vacancies as fewer workers become available. With on-the-job search, the fall in unemployment further raises the search activity of the employed. This keeps vacancy postings higher than they otherwise would be. Adding the two equations for the evolution of sectoral employment, the law of motion for total employment is:

$$
n_{t+1}=(1-\rho) n_{t}+(1-\rho) p\left(\theta_{t}^{g}\right)\left[u_{t}+u_{t}^{b}\left(\left(c^{g} / c^{b}\right)^{1-\mu}-1\right)\right] .
$$

Employment is increasing in the hiring rate $p\left(\theta_{t}^{g}\right)$. Moreover, for given $u_{t}$ search for bad jobs rises with $u_{t}^{b}$. Higher employment next period has a dampening influence, as $u_{t+1}=1-n_{t+1}$ 
is bound to be lower. However, as long as the hiring rate $p\left(\theta_{t}^{g}\right)$ sufficiently rises, and $u_{t}^{b}$ does not fall, employment can rise further. Thus, the volatility of the hiring rate is crucial for propagation.

Employment in the sectors evolves according to:

$$
\begin{aligned}
n_{t+1}^{g} & =(1-\rho)\left[n_{t}^{g}+p\left(\theta_{t}^{g}\right) u_{t}^{g}\right], \\
n_{t+1}^{b} & =(1-\rho)\left[n_{t}^{b}+p\left(\theta_{t}^{g}\right)\left(u_{t}^{b}-e_{t}\right)\right] .
\end{aligned}
$$

While next period's employment in good jobs rises with the hiring rate and the number of the unemployed searching for good jobs, employment in the bad jobs sector falls with the amount of on-the-job search. As long as more of the unemployed search for bad jobs than employed workers search for good jobs, employment can rise when the hiring rate rises. Whether this is the case depends on how much prices continue to signal demand for the output of the low quality sector.

Propagation of the initial shock thus works through two channels. One is the fall in unemployment that arises from the surge in hirings in the period after the shock. The other is the continued need to replace the workers who are flowing to high quality jobs. With unemployment falling substantially, ever fewer workers are searching for good jobs. Indeed, as Figure 2 shows, most of the decline in unemployment shows up in the reduction in searchers for good jobs. In contrast, search for low quality jobs does not fall. The falling competition with the unemployed keeps the match probability, and thus the incentive to search on the job, high for employed job seekers.

\section{Discussion and Robustness}

We now discuss the robustness of the results with respect to aspects of the calibration and to a number of extensions, specifically the calibration of the search elasticity and endogenous intensity of unemployed search.

\subsection{The Role of Search Intensity}

Why does the cyclicality of job-to-job quits change the behavior of the economy so substantially? This is best understood as the result of an interaction between rising search effort and the heterogeneity of vacancy postings. On the one hand, rising search effort raises good firms' incentives to post vacancies. Without employed searchers, the creation of good jobs is constrained by the fall in the number of unemployed searchers and the strong rise in wages. On the other hand, the increasing availability of good jobs further encourages on-the-job 
search. Thus a small rise in productivity leads to large changes in the incentives to search and posting vacancies, which explains that unemployment falls substantially even though competition with employed job seekers rises. Only slowly do these incentives fall back to their steady state levels.

The role of search intensity can be illustrated by varying the elasticity of search effort. The results are depicted in Figure 4, which shows the standard deviation of measures of labor market tightness and the quit rate. As $\sigma$ approaches one from above, the quit rate and labor market tightness become exceedingly volatile. Since the responsiveness of search costs to changing search effort declines, the volatility of job-to-job quits rises. Even though the standard and our modified measures of labor market tightness, $\theta=v / u$ and $\widetilde{\theta}=v /(u+e)$, are almost perfectly correlated, their volatility is strikingly different. While the former is very responsive to changes in $\sigma$, the latter is barely affected. The reason is that as unemployment falls, employed search rises, keeping the incentives for vacancy creation high after a favorable aggregate shock. The theoretical counterpart in our model, $v^{g} /\left(u^{g}+e\right)$, behaves similarly.

As is evident from the impulse responses, the presence of time-varying on-the-job search activity leads to persistent movements of output after shocks to technology. The elasticity of search is, however, only partially responsible for the propagation mechanism in the model. Even with fixed search intensity, productivity shocks are still amplified and propagated in a hump-shaped manner. At the same time, the volatility of vacancies and unemployment falls, as Figure 3 illustrates.

We investigate this issue further by analyzing modifications to our benchmark specification. The impulse response of output is depicted in Figure 5. First, we shut down on-the-job search over the business cycle. That is, we impose $s_{t}=s, \forall t$. While there is still employed search in the steady state - and optimally chosen according to Eq. (14) -, workers are not allowed to adapt their search intensity to changing business cycle conditions. Secondly, we remove the possibility of on-the-job search entirely, thereby only preserving the two-sector, good job/bad job structure. We see clearly the complete lack of propagation in the standard search and matching model. ${ }^{19}$

The endogenous persistence due to on-the-job search is therefore helpful in explaining the autocorrelation patterns in U.S. data. Figure 6 depicts the autocorrelation functions of U.S. GDP growth rates over the period 1948:1-2002:4 and for the three model specifications discussed above. The lack of propagation in the model without on-the-job search is well

\footnotetext{
${ }^{19}$ It is this inability of the search and matching model that has been widely discussed in the literature (see, for instance, Den Haan et. al., 2000).
} 
documented by a flat autocorrelation function around zero. The benchmark model, on the other hand, captures U.S. output dynamics remarkably well, even slightly overpredicting the first-order autocorrelation. But even when search intensity is constant, the autocorrelation pattern by far outperforms the standard model without on-the-job search. ${ }^{20}$

\subsection{Endogenous Search Intensity of the Unemployed}

In the model, the key mechanism is the increasing flow and search activity of employed job seekers. At the same time, the search intensity of unemployed workers is fixed. We argue that this asymmetry does not generate our results. Conceivably, as unemployed search activity rises, their incentives to search for good jobs stay high, thus competing more strongly with the employed searchers. In one-sector models with endogenous search activity (Merz, 1995) this element tends to worsen model performance. In our on-the-job search framework, the mechanism that expands search on-the-job is the fall in unemployment. If unemployed workers were to search more intensively, the unemployment pool would deplete even faster, thus further amplifying the importance of search for employed workers.

It is fairly straightforward to include endogenous search intensity of the unemployed in the baseline model. The asset value of unemployment becomes:

$$
U_{t}^{i}=z-k\left(s_{t}^{u i}\right)+E_{t} \beta_{t+1}\left[s_{t}^{u i} p_{t}^{i}(1-\rho) W_{t+1}^{i}+\left(1-s_{t}^{u i} p_{t}^{i}(1-\rho)\right) U_{t+1}^{i}\right],
$$

where $s_{t}^{u i}$ denotes the search intensity in sector $i$. The first order condition for search intensity is:

$$
k^{\prime}\left(s_{t}^{u i}\right)=\frac{\eta}{1-\eta} p_{t}^{i}(1-\rho) E_{t} \beta_{t}\left[W_{t+1}^{i}-U_{t+1}^{i}\right] .
$$

Arbitrage between sectors implies that $s_{t}^{u i}=s_{t}^{u}$ for all jobs, and again, that $\theta_{t}^{g} c^{g}=\theta_{t}^{b} c^{b}$. It follows that:

$$
k^{\prime}\left(s_{t}^{u}\right)=\frac{\eta}{1-\eta} p_{t}^{g} \frac{c^{g}}{q_{t}^{g}}=\frac{\eta}{1-\eta} \theta_{t}^{g} c^{g} .
$$

As for employed search, search intensity of the unemployed is directly proportional to labor market tightness for good jobs. Furthermore, dividing the conditions for unemployed and employed search intensity, we get:

$$
\frac{k^{\prime}\left(s_{t}^{e}\right)}{k^{\prime}\left(s_{t}^{u}\right)}=\left[1-\left(c^{b} / c^{g}\right)^{1-\mu}\right] .
$$

Assuming the same search cost functions, this condition implies that employed and unemployed search intensity move proportionately in response to shocks.

\footnotetext{
${ }^{20}$ Inclusion of capital is likely to further increase the autocorrelation of output in addition to that achieved by on-the-job search.
} 
First note that higher endogenous search of the unemployed raises the effective search of the unemployed. Define $u_{t}=s_{t}^{u}\left(1-n_{t}\right)$. But its composition is not obvious since $u_{t}=u_{t}^{g}+u_{t}^{b}$. If anything, changes in employment are further amplified, as can be seen from the employment equation:

$$
n_{t+1}=(1-\rho) n_{t}+(1-\rho) p\left(\theta_{t}^{g}\right)\left[u_{t}+u_{t}^{b}\left(\left(c^{g} / c^{b}\right)^{1-\mu}-1\right)\right] .
$$

$u_{t}$ rises, too, as does $u_{t}^{b}$. For given $\theta_{t}^{g}$, employment will rise faster. While this may reduce the periods in which employment and output further rise, it does amplify the impact of the shock. It is not the case that endogenous search of the unemployed works against the effects of on-the-job search.

\subsection{Wage Setting Arrangements and Real Wage Rigidity}

For expositional clarity, we excluded the possibility that employed workers who contact a good firm may be in a stronger bargaining position. As long as the previous job serves as a fallback option, the surplus to the worker is $W_{t}^{g e}-W_{t}^{b}>W_{t}^{g u}-U_{t}$, so that $W_{t}^{g e}>W_{t}^{g u}$ because $W_{t}^{b}>U_{t}$. The superscripts ' $e$ ' and ' $u$ ' indicate the different values for $W_{t}^{g}$ when workers fallbacks differ. Since there is continuous renegotiation, the wages accruing to the worker would fall next period, as the worker cannot return to the previous job. Thus the difference in value during negotiations must be paid lump sum. Such a 'signing bonus' above the wage normally negotiated would have to be $B_{t}=W_{t}^{b}-U_{t}{ }^{21}$

A signing bonus has two effects on the equilibrium. On the one hand, it increases the incentive for employed workers to search. The higher search intensity would somewhat reduce the value of bad jobs, and thus lower $W_{t}^{b}$. On the other hand, good firms who can not distinguish between unemployed and employed workers before contacting them. Therefore, ceteris paribus, vacancies posted would fall due to the probability of having to pay the bonus. This would dominate rejecting the worker and searching another period. How these two effects affect the cyclical response to shocks is not clear, even if they reduce on balance the amount of job-to-job flows.

A second issue is whether turnover can be reduced by higher wages. Such an 'efficiency wage' may be pareto improving, since the reduction in turnover increases the total value of the match. The simple surplus splitting would no longer be equivalent the Nash bargaining

\footnotetext{
${ }^{21}$ We assume here that the previous employer does not make counter-offers, which is not plausible on empirical ground and has been argued not to be in the interest of firms. See Moscarini (2005) and for example, Christensen et al. (2005). But note that Cahuc et al. (2005) use exactly such setup to derive a theory of the wage distribution.
} 
solution, which postulates pareto optimality and a convex bargaining set. However, note that this problem does not arise in our model, because firms cannot affect the current match value by offering a higher wage now. The reason is that workers search behavior is governed by returns to search which accrue only in the next period. Thus the firm should commit to higher wages in the future. With continuous renegotiation, such a commitment cannot be made. Therefore the bargaining set under this assumption is convex and current wage increases are not pareto-improving, so the Nash bargaining solution remains applicable. Only if we were to allow for (at least one-period) wage stickiness can a higher wage in the next period affect turnover decisions today. ${ }^{22}$

Wage rigidity would not only potentially give rise to 'efficiency wages' but also substantially affect the dynamics of the model. It would complement the amplification of vacancies and unemployment and the propagation of shocks. This follows for the reasons emphasized by Hall (2005) and Shimer (2005): rigid wages for new hires keeps the incentives for firms to post vacancies higher as a tightening labor market does not feed back into wages. The volatility of wages, which is already lower in our model with on-the-job search, could be reduced with smaller degrees of real wage rigidity than in the standard model. But the effects of on-the-job search would not be affected.

\section{$7 \quad$ Relation to Previous Work}

In many other models, employed search is mainly varied at the extensive margin and possibly a lump sum is paid for searching. Recent contribution along these lines are Cahuc, PostelVinay, Robin (2005), Nagypal (2005), and Moscarini (2005). Pissarides (2000) is an early example for this modeling strategy. Jobs differ by idiosyncratic productivity levels, drawn from a continuous distribution. With workers choosing whether to search or not, this implies two thresholds in terms of productivity. Below the higher threshold workers have an incentive to search for better employment, participating in the common matching market. New matches start at the highest possible productivity. Below the second threshold, the joint value of the match with the firm is below the parties' outside option, leading to job destruction. Since all jobs are created at the highest possible productivity level, vacancies are the same for employed and unemployed workers. The key difference of our model is the search at the intensive margin, and the persistent difference between job types. Including

\footnotetext{
${ }^{22}$ See Shimer (2006) for a discussion of wage setting in the presence of on-the-job search, and the nature of pareto-improving wage setting when firms can commit to future wage payments.
} 
persistent idiosyncratic shocks in a business cycle model of this type comes at considerable computational costs. ${ }^{23}$

Pissarides' (1994) search model with on-the-job search shares the presence of two different job types, 'good' and 'bad' with ours, and features random search for jobs. An interesting feature is the accumulation of firm-specific capital. Just as idiosyncratic productivity draws, this generates heterogeneity in worker productivities across jobs. Implied is also a threshold in the tenure of workers above which workers do not switch jobs, because starting wages in good jobs are lower than the wage in bad jobs. Thus search is also at the extensive margin, search intensity is constant. Furthermore, relative prices and the interest rate are constant. In Pissarides' model employed job search reduces the volatility of unemployment. Thus this model would not help understand the Hall-Shimer findings of a substantial volatility of the unemployment rate.

Mortensen (1994) simulates a stochastic version of the Mortensen-Pissarides (1994) model, with the addition of on-the-job search, modeled at the extensive margin. The presence of employed search helps in explaining the negative correlation between job creation and destruction. The model also features a procyclical quit rate, with workers being randomly matched to the most productive jobs. Both Pissarides $(1994,2000)$ and Mortensen do not explore prediction of their models for the joint dynamics of vacancies, unemployment and job-to-job flows or the effects on wages.

A second class of models with on-the-job search consider the possibility of endogenous wage distributions arising in the presence of frictions. ${ }^{24}$ However, these models are steady state models, and are based on wage posting. This means that wages do not respond to shocks and are not renegotiated. Burdett and Mortensen (1999) explore the link with interindustry and firm-size wage differentials. Cahuc, Postel-Vinay, Robin (1999) estimate such a model and show how it accounts for a steady state distribution of wages. Christensen et al. (2005) estimate a similar model with endogenous intensity of search. We do not know of any example in the literature that analyses dynamic, that is, stochastic versions of these models. ${ }^{25}$

A final note on the literature that confronted the Mortensen and Pissarides (1994) model with the data. It typically focused on the performance of the model along the dimension it was designed to explain, namely the behavior of job creation and destruction. For example, Cole and Rogerson (1999) find that the model performs well if the steadystate unemployment rate is high. The argument is that the relevant pool of searchers in

\footnotetext{
${ }^{23}$ See Hussey (2005) for such a model.

${ }^{24}$ A key reference is Mortensen (2003).

${ }^{25}$ See also Shimer (2005) who reports that no such analysis has been conducted.
} 
the labor market is high, based on the findings of Blanchard and Diamond (1990). Den Haan, Ramey, and Watson (2000) achieve plausible job flows by modeling endogenous job destruction along with capital. As mentioned, Hall (2003) and Shimer (2003) are the first to consider the ability of the search and matching framework to quantitatively match the cyclical behavior of unemployment and vacancies. In all papers, the performance of the model is enhanced by an assumption that reduces the cyclicality of hiring costs or wages. In our model, it is the presence of employed search.

\section{Conclusion}

We have presented a model of labor market and aggregate dynamics and in which search on-the-job plays a crucial role. It is possible to explain the joint dynamics of vacancies, unemployment, and productivity without resorting to any imperfection other than search and matching frictions. In particular, we do not require wages to be rigid in order to bring the model closer to the data. Instead, in a cyclical upswing, increased search effort by employed workers serves to hold their outside options tame, and keeps costs of job creation more stable for firms. Endogenously, wages are less volatile, and incentives to post vacancies remain high. Unemployed workers incentive to direct search to jobs where they do not compete with employed searchers further amplify these effects.

The model delivers a rich description of the labor market over the business cycle. Booms are times which allow employed workers to upgrade into better jobs, while opening jobs for unemployed workers, albeit of lower quality. The reallocation of labor to more productive units is facilitated by direct job-to-job transitions, rather than requiring movements of workers through the unemployment pool. ${ }^{26}$ One fundamental reason for worker mobility is the heterogeneity of jobs which gives rise to persistent differences in the returns to workers. The creation of good jobs is amplified by the rising intensity of search by employed workers.

The propagation that the model implies may have important implications for business cycle analysis. In the response to a positive productivity shock, output peaked after a number of quarters, not in the first period, as the process for productivity suggests. A higher match probability induces employed workers to search for better jobs. This feeds back into the incentives for firms to continue posting vacancies for a protracted period.

\footnotetext{
${ }^{26} \mathrm{~A}$ different interpretation of the demand structure also comes to mind. The good job-bad job distinction might better be reflecting old and new jobs in a vintage model. In that case, search on the job could accelerate the creation of new vintages at the technological frontier. It would also induce destruction of less productive units, with different implications for the efficiency of creative destruction. See Caballero and Hammour (1995).
} 
Falling unemployment further reduces the competition for good jobs and keeps incentives for search high. Only slowly does this effect appear to fade. Interestingly, we obtain a propagation of shocks that is similar to Den Haan, Ramey, and Watson (2000), even though we do not include capital or a variable destruction rate.

However, the findings are not meant to rule out an potentially important role for (real) wage rigidity. Hall (2005) and Shimer (2005) suggest this as a solution to the empirical difficulties they identified with Mortensen-Pissarides model. Also in our model, wage rigidity would further amplify the cyclical response of vacancies, unemployment and job-to-job flows. Hall (2005) has made an interesting advance modeling wage setting based on social norms, which allows wages even for new hires to be rigid. In previous work, we applied this idea in a monetary business cycle model with search frictions. ${ }^{27}$ The model can also be seen as complementary to work by Nagypal (2005), in which on-the-job search is motivated by workers' perceived match quality. Booms are times where workers are more willing to move to other jobs because of the increased likelihood of finding a better match (independent of actual productivity). This in turn increases the incentives for firms to post vacancies.

\footnotetext{
${ }^{27}$ Krause and Lubik (2007).
} 


\section{Appendix}

\section{A Equation System}

1. Job creation conditions:

$$
\begin{aligned}
\frac{c^{g}}{q_{t}^{g}} & =(1-\rho) E_{t} \beta \frac{c_{t+1}^{-\tau}}{c_{t}^{-\tau}}\left[P_{g, t+1} A_{t+1}-w_{t+1}^{g}+\frac{c^{g}}{q_{t+1}^{g}}\right] \\
\frac{c^{b}}{q_{t}^{b}} & =(1-\rho) E_{t} \beta \frac{c_{t+1}^{-\tau}}{c_{t}^{-\tau}}\left[P_{b, t+1} A_{t+1}-w_{t+1}^{b}+\left(1-s_{t+1} p_{t+1}^{g}\right) \frac{c^{b}}{q_{t+1}^{b}}\right] .
\end{aligned}
$$

2. Wage determination:

$$
\begin{aligned}
w_{t}^{g} & =\eta P_{g, t} A_{t}+(1-\eta) z+\eta p_{t}^{g} \frac{c^{g}}{q_{t}^{g}}, \\
w_{t}^{b} & =\eta P_{b, t} A_{t}+(1-\eta)\left(z+\kappa s_{t}^{\sigma}\right)+\eta\left(1-s_{t}\right) p_{t}^{g} \frac{c^{g}}{q_{t}^{g}} .
\end{aligned}
$$

3. Optimal search intensity:

$$
\kappa \sigma s_{t}^{\sigma-1}=\frac{\eta}{1-\eta} p_{t}^{g}\left(\frac{c^{g}}{q_{t}^{g}}-\frac{c^{b}}{q_{t}^{b}}\right) .
$$

4. Evolution of employment:

$$
\begin{aligned}
n_{t+1}^{g} & \left.=(1-\rho)\left(n_{t}^{g}+m_{t}^{g}\right]\right), \\
n_{t+1}^{b} & =(1-\rho)\left(n_{t}^{b}+m_{t}^{b}-s_{t} p_{t}^{g} n_{t}^{b}\right) .
\end{aligned}
$$

5. Unemployment:

$$
u_{t}=u_{t}^{g}+u_{t}^{b}=1-n_{t}^{g}-n_{t}^{b} .
$$

6. Employed searchers:

$$
e_{t}=s_{t} n_{t}^{b}
$$

7. Matching functions:

$$
\begin{aligned}
& m_{t}^{g}=m\left(v_{t}^{g}, u_{t}^{g}+e_{t}\right)=M_{g}\left(v_{t}^{g}\right)^{1-\mu}\left(u_{t}^{g}+e_{t}\right)^{\mu}, \\
& m_{t}^{b}=m\left(v_{t}^{b}, u_{t}^{b}\right)=M_{b}\left(v_{t}^{b}\right)^{1-\mu}\left(u_{t}^{b}\right)^{\mu} .
\end{aligned}
$$

8. Firm and worker match probabilities:

$$
\begin{aligned}
& q_{t}^{g} \equiv m_{t}^{g} / v_{t}^{g}, \quad q_{t}^{b} \equiv m_{t}^{b} / v_{t}^{b}, \\
& p_{t}^{g}=m_{t}^{g} /\left(u_{t}^{g}+e_{t}\right), \quad p_{t}^{b}=m_{t}^{b} / u_{t}^{b} .
\end{aligned}
$$


9. Arbitrage condition $\left(U_{t}^{g}=U_{t}^{b}=U_{t}\right)$ :

$$
p_{t}^{g} \frac{c^{g}}{q_{t}^{g}}=p_{t}^{b} \frac{c^{b}}{q_{t}^{b}} .
$$

10. Sectoral and aggregate output:

$$
\begin{gathered}
y_{g, t}=A_{t} n_{t}^{g}, \quad y_{b, t}=A_{t} n_{t}^{b}, \\
y_{t}=\left(\alpha y_{b, t}^{\gamma}+(1-\alpha) y_{g, t}^{\gamma}\right)^{1 / \gamma} .
\end{gathered}
$$

11. Prices

$$
\begin{aligned}
& P_{g, t}=(1-\alpha)\left(\frac{y_{g, t}}{y_{t}}\right)^{-(1-\gamma)}, \\
& P_{b, t}=\alpha\left(\frac{y_{b, t}}{y_{t}}\right)^{-(1-\gamma)} .
\end{aligned}
$$

12. Aggregate consumption:

$$
c_{t}=y_{t}-c_{g} v_{g, t}-c_{b} v_{b, t} .
$$

13. arch

$$
\widehat{p}_{t}^{g}-\widehat{m}_{t}^{g}+\frac{u^{g}}{u^{g}+e} \widehat{u}_{t}^{g}+\frac{e}{u^{g}+e} \widehat{e}_{t}=0
$$

14. Aggregate technology

$$
\widehat{A}_{t}=\rho_{A} \widehat{A}_{t-1}+\varepsilon_{A t}
$$




\section{References}

[1] Acemoglu, Daron (2001): "Good Jobs versus Bad Jobs". Journal of Labor Economics, 19(1), 1-21.

[2] Akerlof, George, Andrew Rose, and Janet Yellen (1988): "Job Switching and Job Satisfaction in the U.S. Labor Market". Brookings Papers on Economic Activity, 2, 495-594.

[3] Albaek, Karsten, and Bent Sorensen (1998): "Worker Flows and Job Flows in Danish Manufacturing, 1980-91". The Economic Journal, 108 (November).

[4] Andolfatto, David (1996): "Business Cycles and Labor Market Search". American Economic Review, 86(1), 112-132.

[5] Blanchard, Olivier, and Peter Diamond (1990): "The Cyclical Behavior of the Gross Flows of U.S. Workers". Brookings Papers on Economic Activity, 2, 85-155.

[6] Burgess, Simon M. (1993): "A Model of Competition Between Unemployed and Employed Job Searchers: An Application to the Unemployment Outflow Rate in Britain". The Economic Journal, 103, No. 420, 1190-1204.

[7] Caballero, Ricardo, and Muhamad Hammour (1996): "On the Timing and Efficiency of Creative Destruction". Quarterly Journal of Economics, 111(3) August, 805-52.

[8] Christensen, Bent Jesper, Rasmus Lentz, Dale T. Mortensen, George R. Neumann, Axel Werwatz (2005): "On-the-Job Search and the Wage Distribution". Journal of Labor Economics, vol. 23(1), 31-58.

[9] Cole, Harold, and Richard Rogerson (1999): "Can the Mortensen-Pissarides Matching Model Match the Business Cycle Facts?". International Economic Review, 40(4).

[10] Cooley, Thomas, and Vincenzo Quadrini (1999): "A Neoclassical Model of the Phillips Curve Relation". Journal of Monetary Economics, 44(2), October, 165-193.

[11] Costain, James, and Michael Reiter (2005): "Business Cycles, Unemployment Insurance, and the Calibration of Matching Models". Working paper, Universidat Carlos III

[12] Den Haan, Wouter, Garey Ramey, and Joel Watson (2000): "Job Destruction and Propagation of Shocks". American Economic Review, 90, 3: 482-98 
[13] Fallick, Bruce, and Charles A. Fleischman (2004): "Employer-to-Employer Flows in the U.S. Labor Market: The Complete Picture of Gross Worker Flows". Finance and Economics Discussion Series, \#2004-34, Board of Governors of the Federal Reserve System.

[14] Fujita, Shigeru, and Garey Ramey (2005): "The Dynamic Beveridge Curve", University of California, San Diego, mimeo.

[15] Hagedorn, Michael, and Iurii Manovskii (2005): "The Cyclical Behavior of Equilibrium Unemployment and Vacancies Revisited". University of Pennsylvania mimeo.

[16] Hall, Robert (2003): "Modern Theory of Unemployment Fluctuations: Empirics and Policy Applications". American Economic Review Papers and Proceedings, 93(2), 14550.

[17] Hall, Robert (2005): "Employment Fluctuations with Equilibrium Wage Stickiness". American Economic Review.

[18] Hall, Robert (2006): "Job Loss, Job Finding, and Unemployment in the U.S. Economy over the Past 50 Years". NBER Macroeconomics Annual 2005, 20, 101-137.

[19] Krause, Michael U., and Thomas A. Lubik (2006): "The Cyclical Upgrading of Labor and On-the-job Search". Labour Economics, 13, 459-77.

[20] Krause, Michael U., and Thomas A. Lubik (2007): "The (Ir)relevance of Real Wage Rigidity in the New Keynesian Model with Search Frictions". Journal of Monetary Economics. In Press.

[21] Merz, Monika (1995): "Search in the Labor Market and the Real Business Cycle". Journal of Monetary Economics, 36, 269-300.

[22] Mortensen, Dale T. (1994): "The Cyclical Behavior of Job and Worker Flows". Journal of Economic Dynamics and Control, 18, 1121-42.

[23] Mortensen, Dale T. and Christopher Pissarides (1994): "Job Creation and Job Destruction in the Theory of Unemployment". Review of Economic Studies, 61, 397-415.

[24] Mortensen, Dale T. and Christopher Pissarides (1999): "Job Reallocation, Employment Fluctuations, and Unemployment", in John B. Taylor and Michael Woodford, eds: Handbook of Macroeconomics, vol. 1B, Elsevier North-Holland. 
[25] Moscarini, Giuseppe (2005): "Job Matching and the Wage Distribution". Econometrica, 73(2), 481-516.

[26] Nagypal (2005): "Labour-Market Fluctuations, On-the-Job Search, and the Acceptance Curb". Northwestern University, mimeo.

[27] Okun, Arthur M. (1973): "Upward Mobility in a High-pressure Economy". Brookings Papers on Economic Activity, 1, 207-252.

[28] Parent, Daniel (2000): "Industry-specific Human Capital: Evidence from Displaced Workers". Journal of Labor Economics, 6(4), 306-323.

[29] Petrongolo, Barbara, and Christopher Pissarides (2001): "Looking into the Black Box: A Survey of the Matching Function". Journal of Economic Literature, June, 39(2), $390-431$.

[30] Pissarides, Christopher (1994): "Search Unemployment with on the Job Search". Review of Economic Studies, 61, 457-476.

[31] Pissarides, Christopher (2000): Equilibrium Unemployment Theory. Second edition, MIT Press.

[32] Rotemberg, Julio (2006): "Cyclical Wages in a Search and Bargaining Model with Large Firms". Harvard Business School, mimeo.

[33] Shimer, Robert (2005): "The Cyclical Behavior of Equilibrium Unemployment and Vacancies". American Economic Review.

[34] Shimer, Robert (2006): "On-the-Job Search and Strategic Bargaining". European Economic Review, 50, 811-30.

[35] Sims, Christopher A. (2002): "Solving Linear Rational Expectations Models". Computational Economics, 20 (1-2), 1-20. 
Table 1: U.S. Business Cycle Statistics

\begin{tabular}{|c|c|c|c|c|c|c|c|c|}
\hline & $Y$ & $W$ & $N$ & $\frac{Y}{N}$ & $U$ & $V$ & $\theta$ & $Q R$ \\
\hline & \multicolumn{8}{|c|}{ Standard Deviation } \\
\hline & 1.62 & 0.69 & 0.81 & 0.83 & 6.90 & 8.27 & 14.96 & 9.81 \\
\hline & \multicolumn{8}{|c|}{ Cross-Correlations } \\
\hline & $Y$ & $W$ & $N$ & $\frac{Y}{N}$ & $U$ & $V$ & $\theta$ & $Q R$ \\
\hline$Y$ & 1 & 0.57 & 0.82 & 0.69 & -0.87 & 0.92 & 0.91 & 0.91 \\
\hline$W$ & - & 1 & 0.27 & 0.66 & -0.42 & 0.51 & 0.47 & 0.05 \\
\hline$N$ & - & - & 1 & 0.16 & -0.93 & 0.88 & 0.91 & 0.91 \\
\hline$\frac{Y}{N}$ & - & - & - & 1 & -0.34 & 0.49 & 0.43 & 0.44 \\
\hline$\stackrel{N}{U}$ & - & - & - & - & 1 & -0.95 & -0.98 & -0.93 \\
\hline$V$ & - & - & - & - & - & 1 & 0.99 & 0.94 \\
\hline$\theta$ & - & - & - & - & - & - & 1 & 0.95 \\
\hline$Q R$ & & & & & & & & 1 \\
\hline
\end{tabular}


Table 2: Model Parameters and Calibration

\begin{tabular}{lll}
\hline \hline Parameter & Value & Description \\
\hline & & \\
$\mu$ & 0.4 & Match Elasticity \\
$M_{g}$ & 0.6 & Level Parameter \\
$M_{b}$ & 0.6 & Level Parameter \\
$c_{g}$ & 0.16 & Good Job Creation Cost \\
$c_{b}$ & 0.04 & Bad Job Creation Cost \\
$\rho$ & 0.1 & Separation Rate \\
$\sigma$ & 1.1 & Search Elasticity \\
$\eta$ & 0.5 & Nash Bargaining Share \\
$\alpha$ & 0.4 & CES-Weight \\
$\beta$ & 0.98 & Discount Factor \\
$\tau$ & 1 & Intertemporal Substitution Elasticity \\
$u$ & 0.12 & Unemployment Rate \\
$\zeta$ & 0.06 & Quit Rate \\
$z$ & 0.39 & Value of Home Production \\
$\kappa$ & 0.04 & Search Cost Function Parameter \\
& & \\
\hline \hline
\end{tabular}


Table 3: Benchmark Simulation

\begin{tabular}{|c|c|c|c|c|c|c|c|c|c|}
\hline \multicolumn{10}{|c|}{ Standard Deviations } \\
\hline & $Y$ & $W$ & $N$ & $\frac{Y}{N}$ & $U_{(\mathrm{re}}$ & $\begin{array}{l}V \\
\text {. to } Y)\end{array}$ & $\theta$ & $\theta_{n}$ & $Q R$ \\
\hline & 1.62 & 0.19 & 0.56 & 0.27 & 6.09 & 5.43 & 11.17 & 2.57 & 10.05 \\
\hline \multicolumn{10}{|c|}{ Cross-Correlations } \\
\hline & & $Y$ & $W$ & $N$ & $\frac{Y}{N}$ & $U$ & $V$ & $\theta$ & $Q R$ \\
\hline$Y$ & & 1 & 0.83 & 0.99 & 0.97 & -0.99 & 0.93 & 0.99 & 0.96 \\
\hline$W$ & & - & 1 & 0.81 & 0.86 & -0.75 & 0.97 & 0.88 & 0.94 \\
\hline$N$ & & - & - & 1 & 0.54 & -1.0 & 0.87 & 0.97 & 0.92 \\
\hline$Y / N$ & & - & - & - & 1 & -0.54 & 0.84 & 0.87 & 0.96 \\
\hline$U$ & & - & - & - & - & 1 & -0.87 & -0.97 & -0.92 \\
\hline$V$ & & - & - & - & - & - & 1 & 0.96 & 0.99 \\
\hline$\theta$ & & - & - & - & - & - & - & 1 & 0.98 \\
\hline$Q R$ & & - & - & - & - & - & - & - & 1 \\
\hline
\end{tabular}



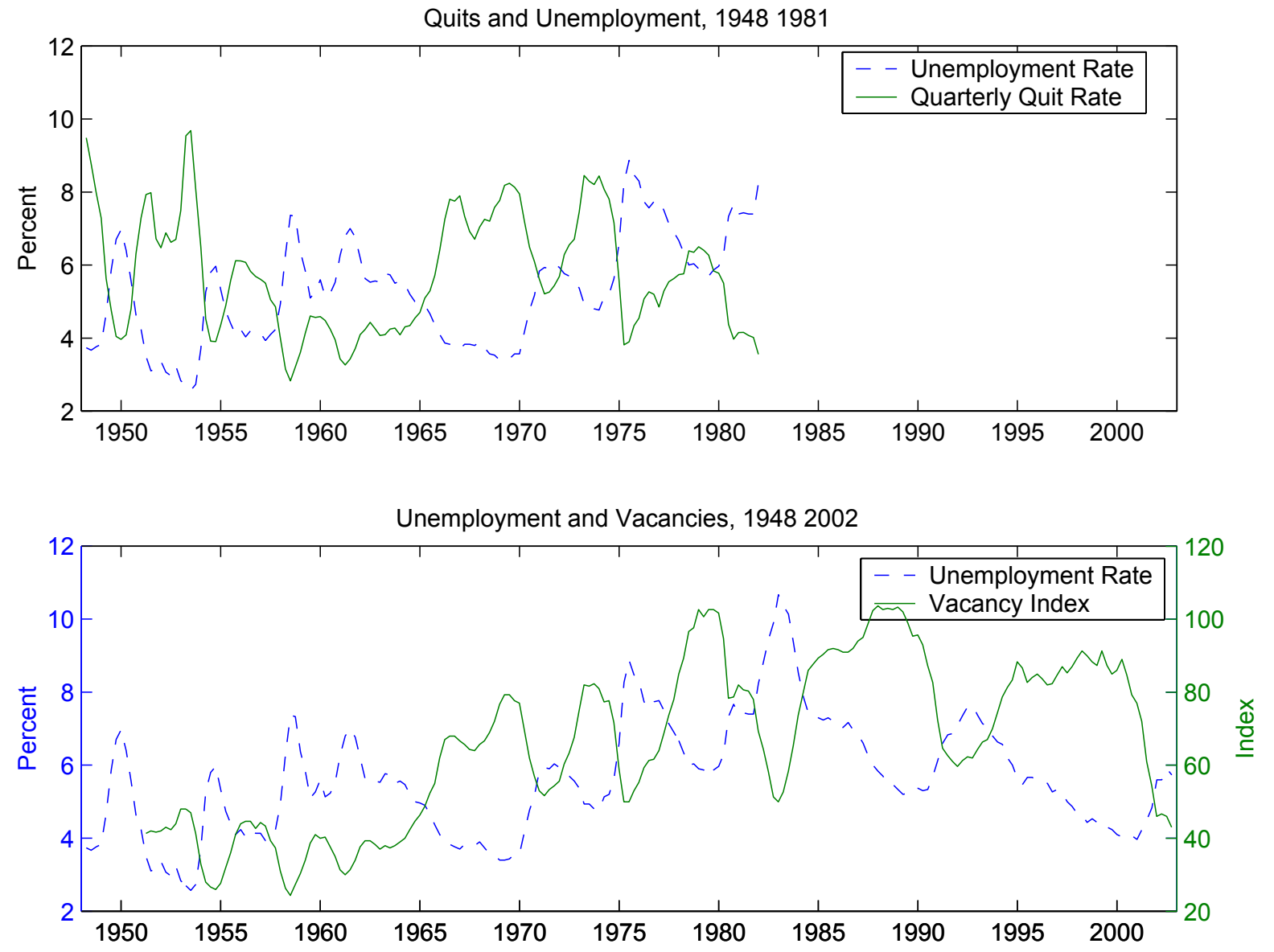

Figure 1: Vacancies, Unemployment and Quits 

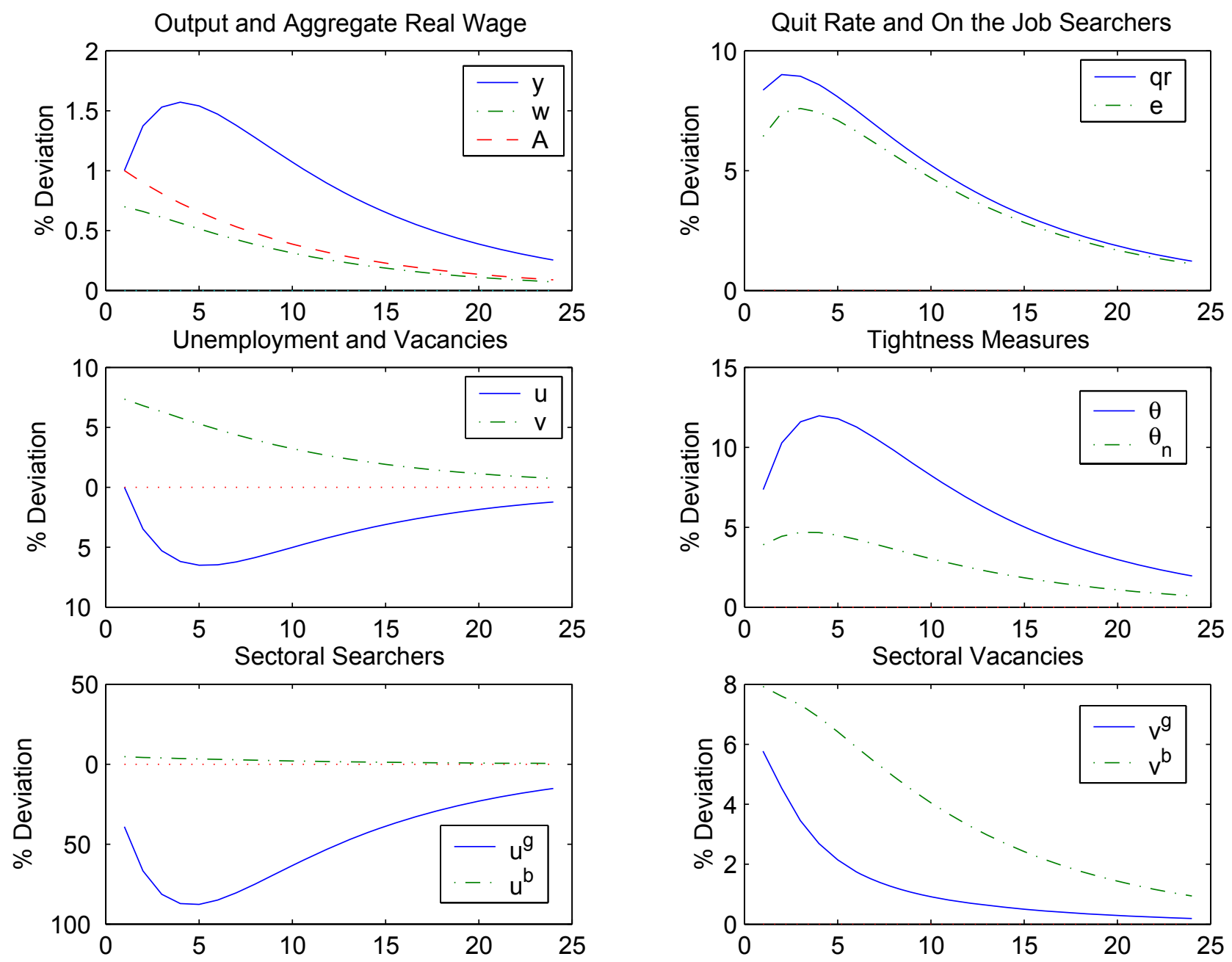

Figure 2: Impulse Response Functions to a 1\% Productivity Shock 

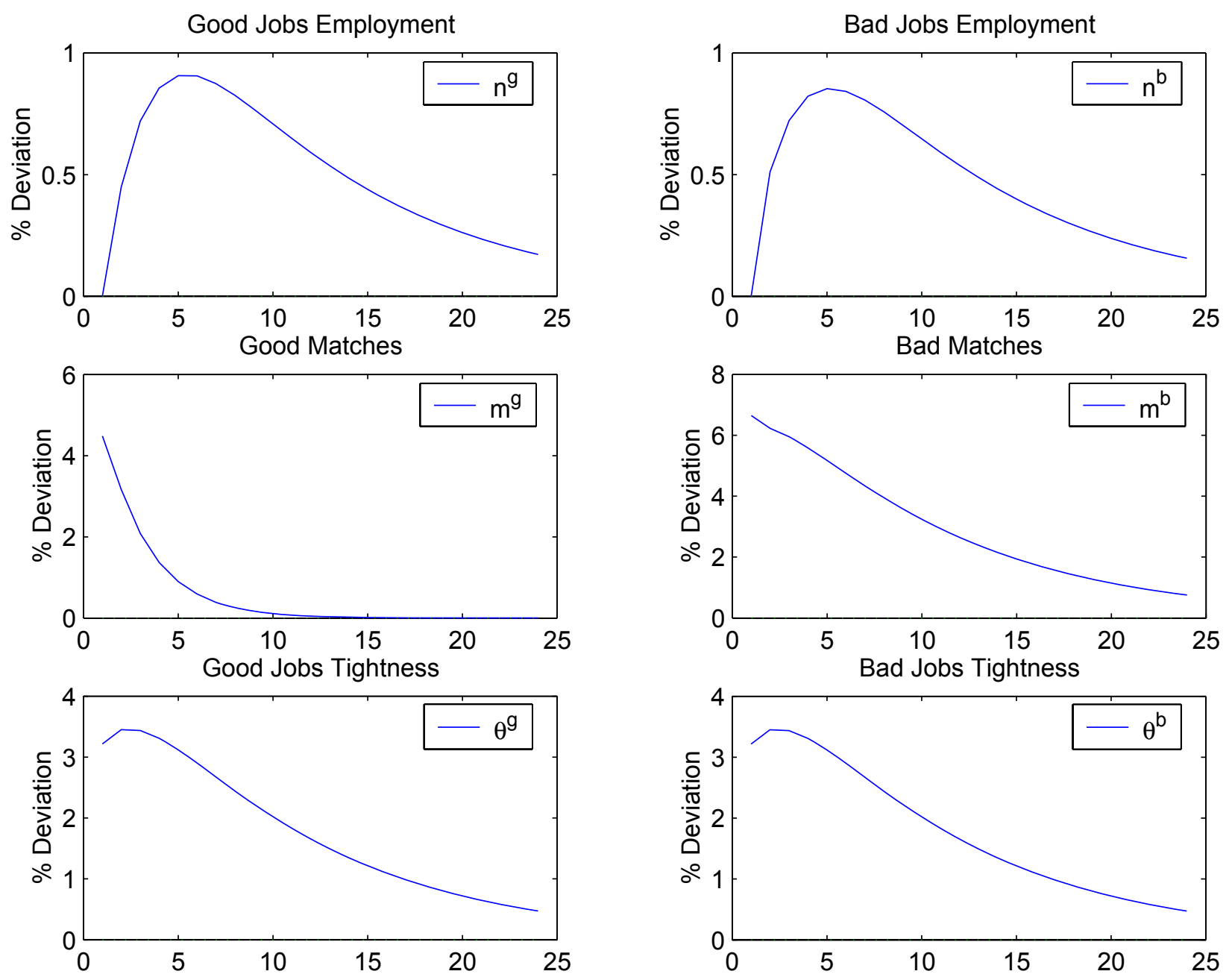

Figure 3: Impulse Response Functions to a 1\% Productivity Shock 


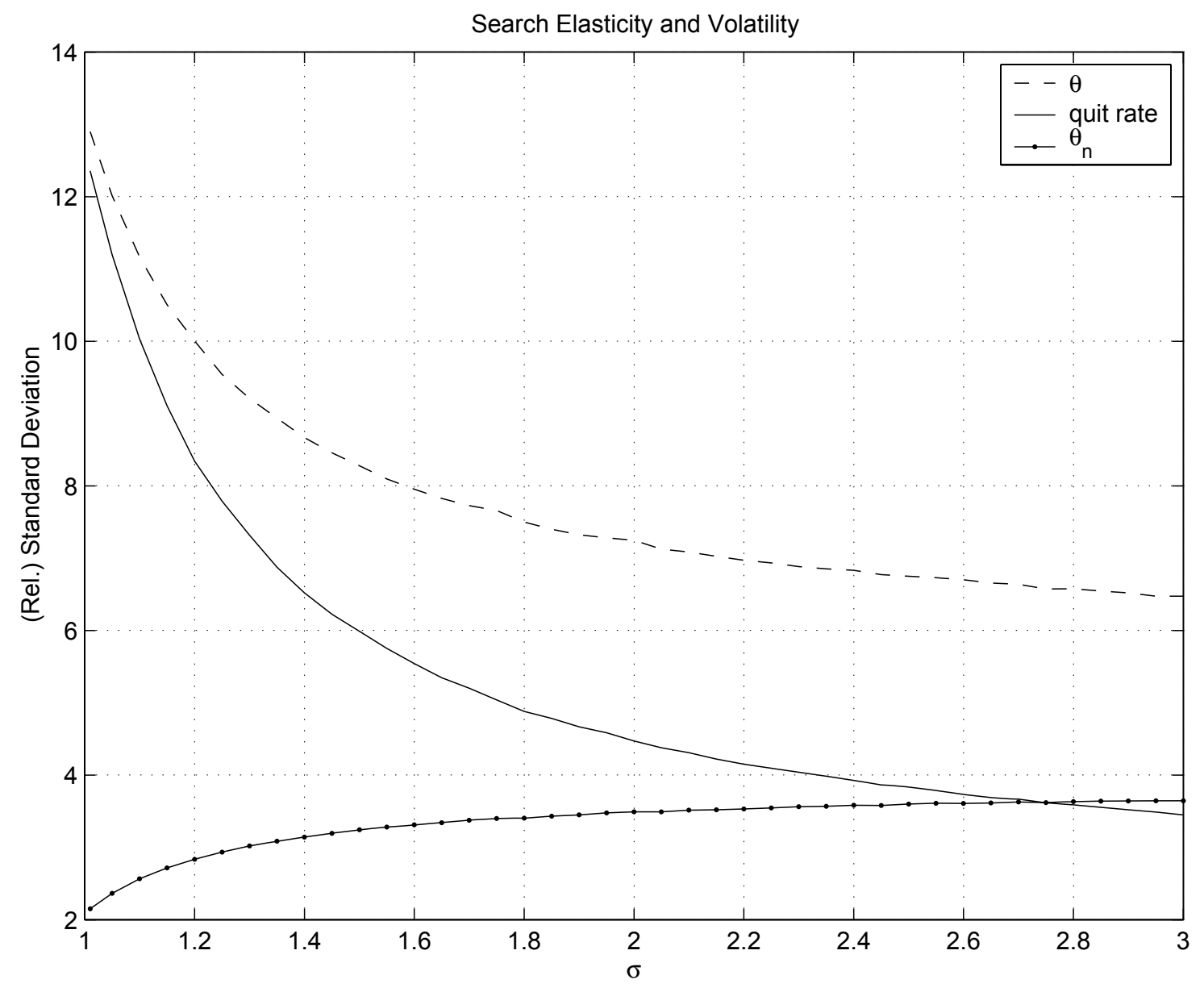

Figure 4: Search Elasticity and Aggregate Volatilities 


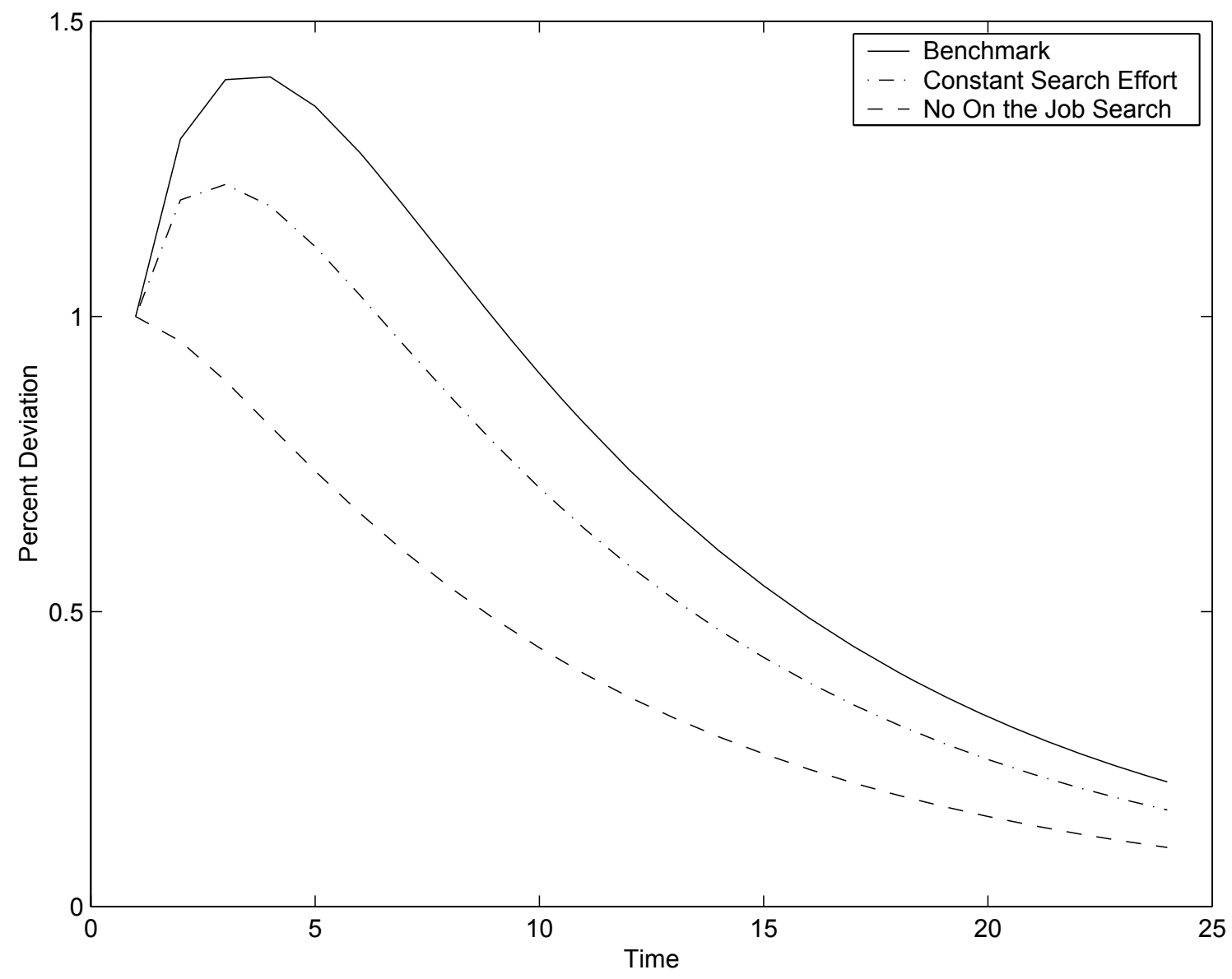

Figure 5: Impulse Responses of Output to a 1\% Productivity Shock 


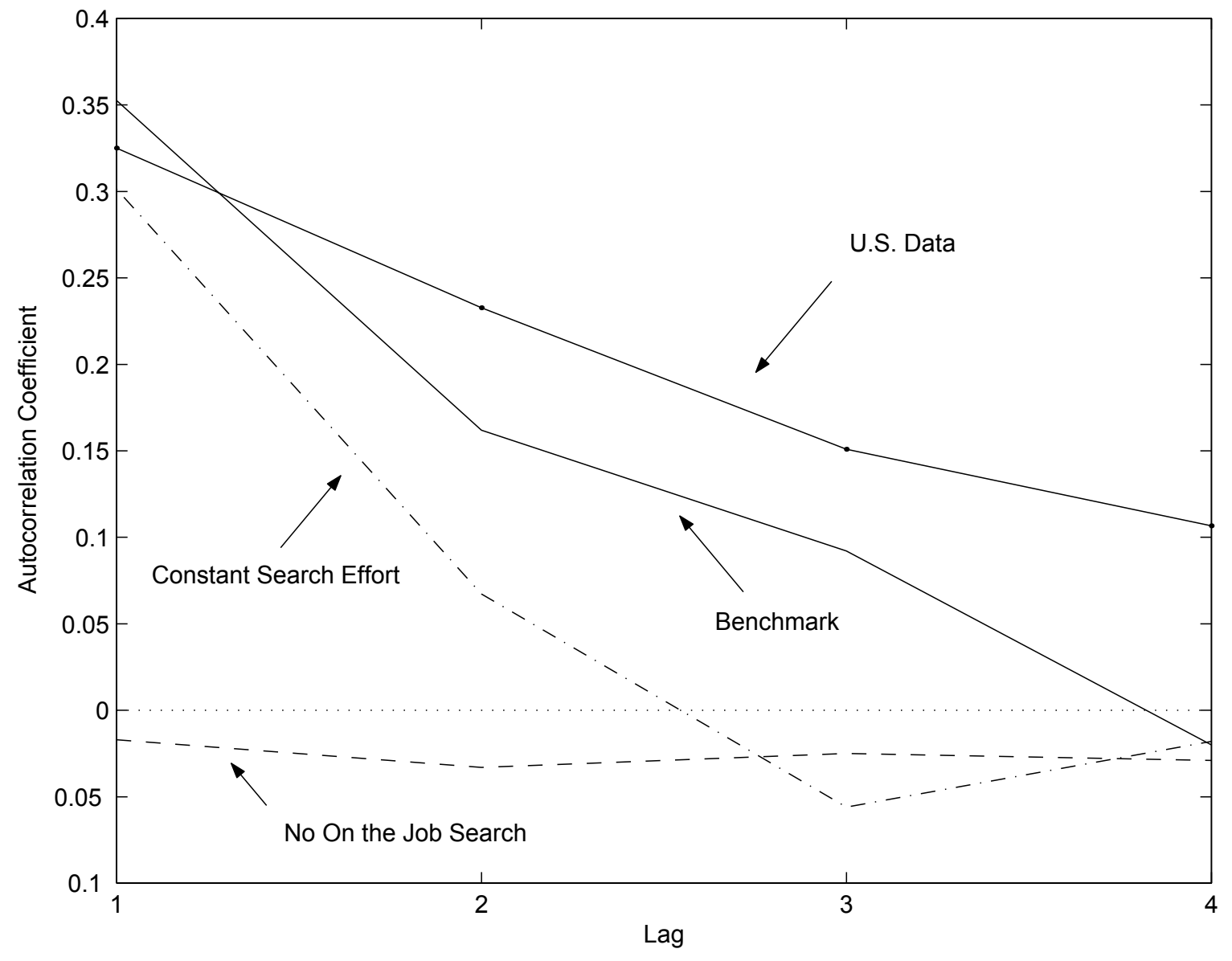

Figure 6: Autocorrelations of Output Growth Rates 


\section{European Central BankWorking Paper Series}

For a complete list of Working Papers published by the ECB, please visit the ECB's website (http://www.ecb.int)

745 "Market discipline, financial integration and fiscal rules: what drives spreads in the euro area government bond market?" by S. Manganelli and G.Wolswijk,April 2007.

746 “U.S. evolving macroeconomic dynamics: a structural investigation” by L. Benati and H. Mumtaz, April 2007.

747 "Tax reform and labour-market performance in the euro area: a simulation-based analysis using the New Area-Wide Model” by G. Coenen, P. McAdam and R. Straub,April 2007.

748 "Financial dollarization: the role of banks and interest rates" by H. S. Basso, O. Calvo-Gonzalez and M. Jurgilas, May 2007.

749 "Excess money growth and inflation dynamics" by B. Roffia and A. Zaghini, May 2007.

750 "Long run macroeconomic relations in the global economy" by S. Dees, S. Holly, M. H. Pesaran and L.V. Smith, May 2007.

75I "A look into the factor model black box: publication lags and the role of hard and soft data in forecasting GDP” by M. Bańbura and G. Rünstler, May 2007.

752 "Econometric analyses with backdated data: unified Germany and the euro area" by E. Angelini and M. Marcellino, May 2007.

753 “Trade credit defaults and liquidity provision by firms” by F. Boissay and R. Gropp, May 2007.

754 "Euro area inflation persistence in an estimated nonlinear DSGE model" by G.Amisano and O.Tristani, May 2007.

755 "Durable goods and their effect on household saving ratios in the euro area" by J. Jalava and I. K. Kavonius, May 2007.

756 "Maintaining low inflation: money, interest rates, and policy stance” by S. Reynard, May 2007.

757 "The cyclicality of consumption, wages and employment of the public sector in the euro area" by A. Lamo, J. J. Pérez and L. Schuknecht, May 2007.

758 "Red tape and delayed entry" by A. Ciccone and E. Papaioannou, June 2007.

759 "Linear-quadratic approximation, external habit and targeting rules" by P. Levine, J. Pearlman and R. Pierse, June 2007.

760 "Modelling intra- and extra-area trade substitution and exchange rate pass-through in the euro area" by A. Dieppe and T.Warmedinger, June 2007.

$76 I$ "External imbalances and the US current account: how supply-side changes affect an exchange rate adjustment” by P. Engler, M. Fidora and C. Thimann, June 2007.

762 "Patterns of current account adjustment: insights from past experience" by B.Algieri and T. Bracke, June 2007. 
763 "Short- and long-run tax elasticities: the case of the Netherlands" by G.Wolswijk, June 2007.

764 "Robust monetary policy with imperfect knowledge" by A. Orphanides and J. C. Williams, June 2007.

765 "Sequential optimization, front-loaded information, and U.S. consumption" by A.Willman, June 2007.

766 "How and when do markets tip? Lessons from the Battle of the Bund" by E. Cantillon and P.-L.Yin, June 2007.

767 “Explaining monetary policy in press conferences” by M. Ehrmann and M. Fratzscher, June 2007.

768 "A new approach to measuring competition in the loan markets of the euro area" by M. van Leuvensteijn, J.A. Bikker,A. van Rixtel and C. Kok Sørensen, June 2007.

769 “The 'Great Moderation' in the United Kingdom” by L. Benati, June 2007.

770 "Welfare implications of Calvo vs. Rotemberg pricing assumptions" by G. Lombardo and D. Vestin, June 2007.

77I "Policy rate decisions and unbiased parameter estimation in typical monetary policy rules" by J. Podpiera, June 2007.

772 "Can adjustment costs explain the variability and counter-cyclicality of the labour share at the firm and aggregate level?” by P. Vermeulen, June 2007.

773 "Exchange rate volatility and growth in small open economies at the EMU periphery" by G. Schnabl, July 2007.

774 "Shocks, structures or monetary policies? The euro area and US after 200 I" by L. Christiano, R. Motto and M. Rostagno, July 2007.

775 "The dynamic behaviour of budget components and output" by A. Afonso and P. Claeys, July 2007.

776 “Insights gained from conversations with labor market decision makers” by T. F. Bewley, July 2007.

777 “Downward nominal wage rigidity in the OECD” by S. Holden and F.Wulfsberg, July 2007.

778 “Employment protection legislation and wages” by M. Leonardi and G. Pica, July 2007.

779 "On-the-job search and the cyclical dynamics of the labor market" by M. U. Krause and T.A. Lubik, July 2007. 


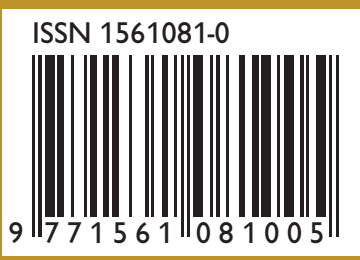

